\title{
Research Square \\ Estimating an Achievable Target Price to \\ Regenerate Bio-Oils Post Hydrogen Sulfide Removal
}

\section{Emma C. Brace}

Department of Agricultural \& Biological Engineering, Purdue University, $125 \mathrm{~S}$. State St., West Lafayette, IN 47907, USA. Laboratory of Renewable Resources Engineering, Purdue University, 500 Central Dr., West Lafayette, IN 47907, USA

Abigail S. Engelberth ( $\sim$ aengelbe@purdue.edu )

Agricultural \& Biological Engineering Environmental \& Ecological Engineering Laboratory of Renewable Resources Engineering https://orcid.org/0000-0002-8150-0562

\section{Research}

Keywords: Biomaterials, bioreactor design, bioseparations, biotechnology, modeling

Posted Date: December 4th, 2020

DOI: https://doi.org/10.21203/rs.3.rs-117437/v1

License: (c) (1) This work is licensed under a Creative Commons Attribution 4.0 International License. Read Full License 
Title: Estimating an Achievable Target Price to Regenerate Bio-Oils Post Hydrogen Sulfide Removal

Authors: Emma C. Brace ${ }^{1,2}$ and Abigail S. Engelberth ${ }^{1,2,3^{*}}$

1. Department of Agricultural \& Biological Engineering, Purdue University, 125 S. State St., West Lafayette, IN 47907, USA

2. Laboratory of Renewable Resources Engineering, Purdue University, 500 Central Dr., West Lafayette, IN 47907, USA

3. Environmental \& Ecological Engineering, Purdue University, 500 Central Dr., West Lafayette, IN 47907, USA

*Corresponding author's email address: aengelbe@purdue.edu

\begin{abstract}
Bio-oils offer valuable use as bio-solvents for removing hydrogen sulfide $\left(\mathrm{H}_{2} \mathrm{~S}\right)$ from natural gas. Preceding bench-scale studies indicate that greater than $90 \%$ of $\mathrm{H}_{2} \mathrm{~S}$ can be removed from a gas stream; economic analysis of such a process is necessary to determine solvent regenerative power required and price limits on a to-be-determined solvent regeneration scheme. With a processing goal $1000 \mathrm{kmol} / \mathrm{h}$ of sour gas and removing $99.9 \%$ of $\mathrm{H}_{2} \mathrm{~S}$ from gas streams at variable feed concentration, design of an absorption unit to process natural gas using bio-oils was carried out through equilibrium stage analysis. Comparison to conventional amine gas treating was used as a cost threshold for gas treatment. The economic viability of using bio-oils as gas sweetening agents depends on capability of regenerating and recycling more than $98 \%$ of the soybean oil bio-solvent to compete with amine gas treating, the most popular industrial method.
\end{abstract}

\title{
Keywords
}

Biomaterials; bioreactor design; bioseparations; biotechnology; modeling 


\section{Introduction}

The use of bio-oils - conventional soybean, high oleic soybean, canola, and sunflower - to remove hydrogen sulfide $\left(\mathrm{H}_{2} \mathrm{~S}\right)$ from a gaseous mixture has been demonstrated ${ }^{1}$ and has potential for use in the natural gas industry to sweeten gas as it is extracted. High concentrations of $\mathrm{H}_{2} \mathrm{~S}$ in natural gas render it sour, with sour gas defined as natural gas containing anywhere from 4 ppmv to thousands of parts per million $\mathrm{H}_{2} \mathrm{~S}^{2}{ }^{2}$ Bio-oils have demonstrated the ability to remove up to $90 \%$ of gaseous $\mathrm{H}_{2} \mathrm{~S}$ from a gas stream at the bench-scale ${ }^{1}$ and could be used in a scheme similar to the industrially prevalent amine gas treating methods. ${ }^{3,4}$

In an effort to evaluate if further investigation into bio-oils as gas sweetening agents could yield a viable process, the economic feasibility must be assessed. The present work aims to determine the number of stages required to remove $99.9 \%$ of $\mathrm{H}_{2} \mathrm{~S}$ from methane feed gas with varying concentrations of $\mathrm{H}_{2} \mathrm{~S}$, to examine the capital costs, determine the required regenerative power of the bio-oil solvent, and ultimately determine the maximum cost of regenerating and recycling the bio-oils to be competitive with currently implemented gas processing methods.

\section{Methods}

In considering the price of using bio-oils as extraction solvents for treating sour gas and removing $\mathrm{H}_{2} \mathrm{~S}$, the cost of such a process would need to be less than or equal to the existing industrial processes for treating sour natural gas. Industrial natural gas production plants using amine gas treating methods typically spend $\$ 4 / G J$ on gas treating. ${ }^{5}$ To draw a comparison between using biooils such as conventional soybean or high-oleic soybean oil as the gas sweetening solvent, the factors that impact the cost of the process must be verified. The cost of the absorption unit - an extraction column - is a key part of the capital cost estimation. By constructing equilibrium stage diagrams an extraction column can be designed, which can then be used to estimate capital costs. 
Sensitivity analysis, with respect to bio-oil solvent regeneration capability, can also aid in understanding how reliant the process viability is on being able to recycle the bio-oil solvents. Recovered sulfur could be a lucrative byproduct, as sulfur is valued at more than $\$ 200 /$ ton as a chemical building block. ${ }^{6}$ As a baseline comparison, the overall cost can be set equal to the current cost of amine gas treatment $(\$ 4 / \mathrm{GJ})$; from there, the total maximum cost of bio-oil solvent regeneration/sulfur recovery units can be calculated and the feasibility of developing a process within those cost constraints can be evaluated.

To construct the equilibrium stage diagrams, experimentally determined partition coefficients for $\mathrm{H}_{2} \mathrm{~S}$ in each bio-oil were used. ${ }^{1}$ Feed gas concentrations of 40 and $400 \mathrm{ppm} \mathrm{H}_{2} \mathrm{~S}$ in nitrogen were examined with $99.9 \%$ removal of $\mathrm{H}_{2} \mathrm{~S}$ as the target. A $40 \mathrm{ppm}_{2} \mathrm{~S}$ feed gas concentration would be $2.6 \mathrm{~mol} \% \mathrm{H}_{2} \mathrm{~S}$ and $97.4 \%$ methane; a $400 \mathrm{ppm} \mathrm{H}_{2} \mathrm{~S}$ feed gas concentration would be $20 \mathrm{~mol} \%$ $\mathrm{H}_{2} \mathrm{~S}$ and $80 \mathrm{~mol} \%$ methane. These concentrations were chosen to examine the capability of the bio-oil solvents to achieve $99.9 \% \mathrm{H}_{2} \mathrm{~S}$ removal from gas with low and high starting $\mathrm{H}_{2} \mathrm{~S}$ concentrations, as well as to compare with bench-scale studies carried out using $40 \mathrm{ppm}_{2} \mathrm{~S}$. A $1000 \mathrm{kmol} / \mathrm{h}$ gas feed rate was applied for all simulations, which is on par with flow rates and volumes used industrially in amine gas treating. A graphical solution method ${ }^{7}$ was used to determine the optimum flow rate for the bio-oil solvents and the number of equilibrium stages necessary for removing $99.9 \%$ of the $\mathrm{H}_{2} \mathrm{~S}$ from different feed gas concentrations using soybean oil or high oleic soybean oil as the sorption solvent. The Kremser method ${ }^{7,8}$ was then used to evaluate the percent of $\mathrm{H}_{2} \mathrm{~S}$ absorbed at each theoretical equilibrium stage for different absorbent flow rates and feed gas compositions: the parameters used are shown in Table 1. 
Table 1. Flow rates and compositions used for graphical and Kremser methods of equilibrium stage analyses.

\begin{tabular}{ll}
\hline Parameter & Value \\
\hline Feed gas flow rate & $1000 \mathrm{kmol} / \mathrm{h}$ \\
\hline Feed gas composition & $40 \mathrm{ppm}(2.6 \mathrm{~mol} \%)$ or $400 \mathrm{ppm}(20 \mathrm{~mol} \%) \mathrm{H}_{2} \mathrm{~S}$ \\
\hline Sorbent flow rate & $96-250 \mathrm{kmol} / \mathrm{h}$ \\
\hline Sorbent composition & $100 \%$ bio-oil: soybean or high oleic soybean \\
\hline
\end{tabular}

To set a maximum total price, comparisons were drawn between similar amine gas treating processes employing an absorption unit and solvent regeneration and recycle units. ${ }^{2-4,6}$ Industrially popular amine gas treating works similar to the scheme proposed here, with alkylamines (most commonly diethanolamine or monoethanolamine) acting as an $\mathrm{H}_{2} \mathrm{~S}$ and $\mathrm{CO}_{2}$ absorbent in an extraction column, while the gases are stripped off in a stripping column to regenerate the amine solvents. ${ }^{3-5}$

\section{Results \& Discussion}

Economic evaluation of processing sour natural gas using bio-oils is necessary in determining economic viability of such a process before taking efforts to scale up a bench-scale process. Methods to regenerate and recycle the bio-oils and recover sulfur are not yet fully understood, so a total price for the process is set equal to that of existing technologies (such as amine gas treating). After subtracting capital costs and solvent costs from the total price limit, the maximum cost of solvent regeneration and sulfur precipitation was calculated. Discussion regarding the feasibility of developing a process to meet these cost constraints is included.

This study aims to investigate the number of stages necessary for $99.9 \%$ removal of $\mathrm{H}_{2} \mathrm{~S}$ from varying feed gas concentrations, the price of the extraction column and initial solvent cost, the potential revenue through conversion of $\mathrm{H}_{2} \mathrm{~S}$ and sale of sulfur, and impact of solvent lifetime and regeneration. Figure 1 shows a general schematic of the proposed process. 


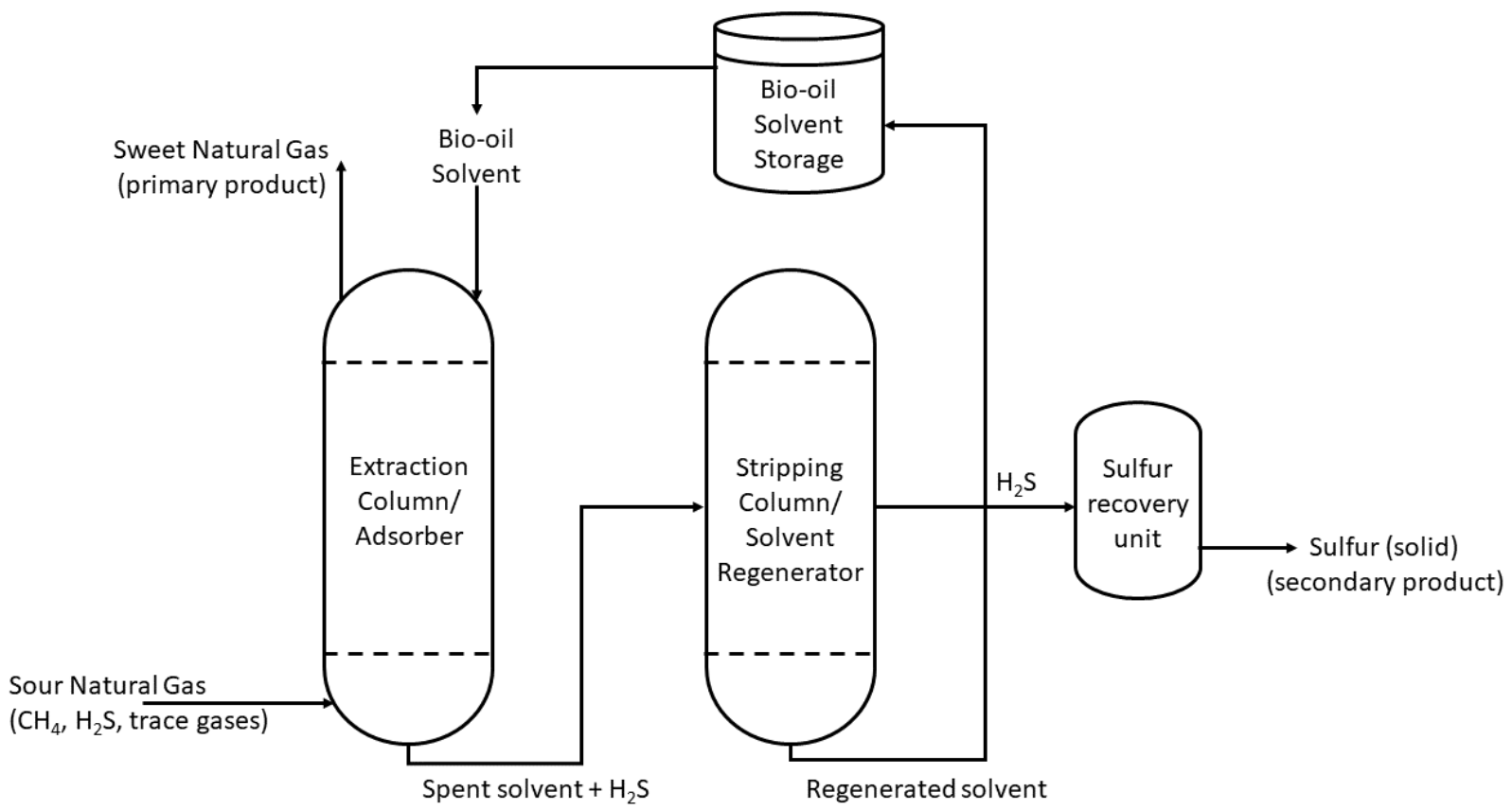

Figure 1. Schematic diagram of a potential process using bio-oil as an extraction solvent to remove $\mathrm{H}_{2} \mathrm{~S}$ from sour natural gas. An extraction column and solvent cost will be the primary initial costs and will be used to set a limit on how much the solvent regeneration/sulfur recovery units could cost in order for the total process to be economically viable.

\section{Estimation of Stages and Stage Efficiency for Recovering $\mathrm{H}_{2} \mathrm{~S}$ as Concentration Varies}

To determine the number of stages necessary for handling sour natural gas using bio-oil extraction solvents, varying concentrations of $\mathrm{H}_{2} \mathrm{~S}$ in methane were examined (Table 1 in Methods). A graphical method was implemented to determine the optimal flow rates of the liquid absorbent feed and the number of stages required to achieve $99.9 \%$ removal of $\mathrm{H}_{2} \mathrm{~S}$ from the feed gas. Partition coefficient values $(K)$ for soybean oil $(\mathrm{SBO}, K=0.08)$ and high oleic soybean oil (HOSBO, $K=0.1$ ) were previously experimentally determined for $\mathrm{H}_{2} \mathrm{~S}$ partitioning in bio-oils. ${ }^{1}$ Two concentrations of $\mathrm{H}_{2} \mathrm{~S}$ were chosen for study: $40 \mathrm{ppm}$ (2.6 mol\%), a proximate value for the bench scale equilibrium experiments, and $400 \mathrm{ppm}$ ( $20 \mathrm{~mol} \%)$, to evaluate capability to sweeten sour gas streams at the more concentrated end of the spectrum. Figure 2 shows the absorption model framework for graphical evaluation. 
(a)

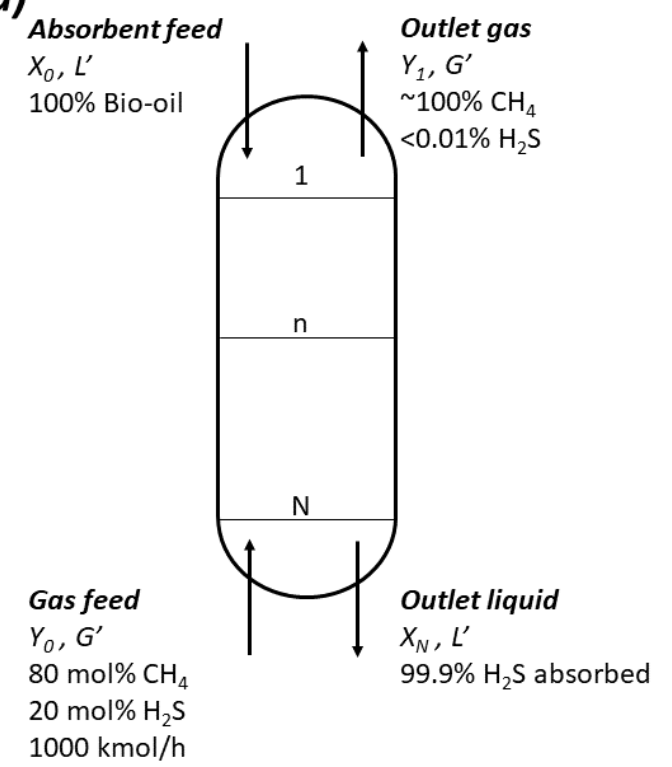

(b)

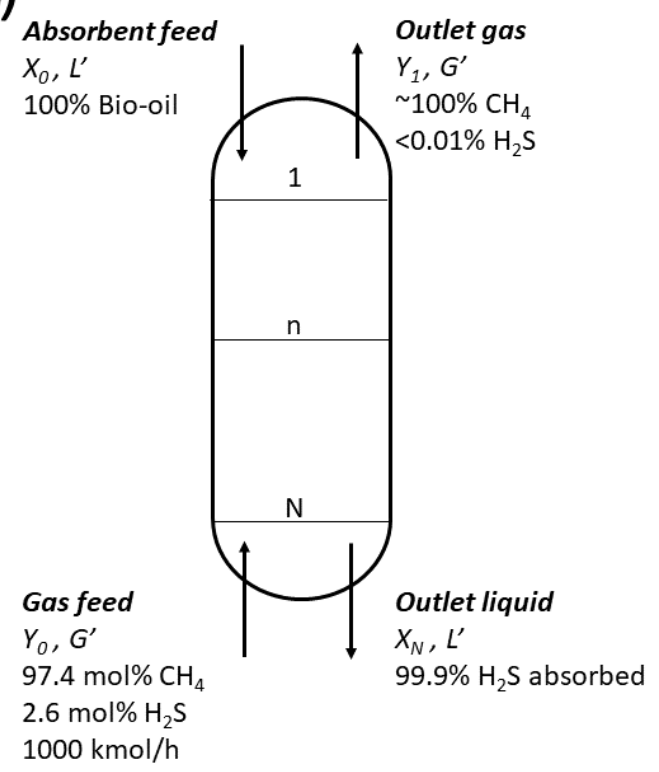

Figure 2. A tray column absorption unit operation with a gas feed of either (a) 20 mol\% $\mathrm{H}_{2} \mathrm{~S}$ ( $\sim 400 \mathrm{ppmv}$ ) or (b) $2.6 \mathrm{~mol} \% \mathrm{H}_{2} \mathrm{~S}(\sim 40 \mathrm{ppmv})$. Based on a feed gas flowrate $\left(G^{\prime}\right)$ of $1000 \mathrm{kmol} / \mathrm{h}$, the absorbent flow rate $L$ ' and number of stages $N$ necessary to achieve $99.9 \%$ removal of the $\mathrm{H}_{2} \mathrm{~S}$ from the gas feed was determined using a graphical method.

For design of an absorption unit akin to the depiction in Figure 2, Equations 1-3 were used to determine the minimum absorbent flow rate, $L^{\prime}{ }_{\min }$, the optimum absorbent flow rate, $1.5 L^{\prime}{ }_{\min }$, and the operating lines. The minimum absorbent flow-rate, Equation 1, is a function of the partition coefficient $K_{N}$ and the flow rate $G^{\prime}$ of the gas feed. The optimum absorbent flow rate, $L^{\prime}$, in Equation 2, is recognized to be a multiple of the minimum absorbent flow rate, $L^{\prime}{ }_{\min }$, and is typically estimated to be close to optimal at $1.5 \times L^{\prime}{ }_{\text {min }}{ }^{7}$ Depending on which multiple of $L^{\prime}{ }_{\min }$ is chosen for $L^{\prime}$, different operating lines can be graphed according to Equation 3.

Minimum absorbent flowrate

Optimum absorbent flowrate

Absorber operating lines

$$
\begin{gathered}
L_{\text {min }}^{\prime}=G^{\prime} K_{N} \\
L^{\prime}=1.5 \times L_{\text {min }}^{\prime} \\
X_{0} L^{\prime}+Y_{N+1} G^{\prime}=X_{N} L^{\prime}+Y_{1} G^{\prime}
\end{gathered}
$$


The equilibrium line was constructed using an experimentally determined $K_{N}$ value of $0.1 \mathrm{mg} \mathrm{H}_{2} \mathrm{~S}$

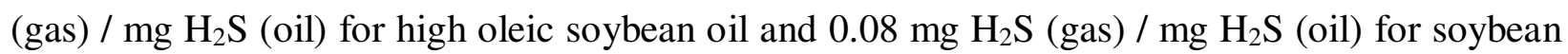
oil. ${ }^{1}$ The equilibrium line equation used in the graphical solutions is shown in Equation $4 .^{7}$ The concentration of $\mathrm{H}_{2} \mathrm{~S}$ in the gas $(X)$ and the concentration in the absorbent liquid $(Y)$ at any stage $(N)$ is a function of the partition coefficient $(K)$.

Equilibrium line $\quad K_{N}=\frac{Y_{N+1} /\left(1+Y_{N+1}\right)}{X_{N} /\left(1+X_{N+1}\right)}$

The graphical solution for (a) $20 \mathrm{~mol}^{2} \mathrm{H}_{2} \mathrm{~S}$ absorbed by high oleic soybean oil, (b) $2.6 \mathrm{~mol} \% \mathrm{H}_{2} \mathrm{~S}$ absorbed by high oleic soybean oil, (c) $20 \mathrm{~mol} \% \mathrm{H}_{2} \mathrm{~S}$ absorbed by soybean oil, and (d) $2.6 \mathrm{~mol} \%$ $\mathrm{H}_{2} \mathrm{~S}$ absorbed by soybean oil are shown in Figure 3. Table 2 summarizes the conclusions for $1.5 L^{\prime}{ }_{\min }$ and $N$ depending on the absorbent and feed concentration of $\mathrm{H}_{2} \mathrm{~S}$. 

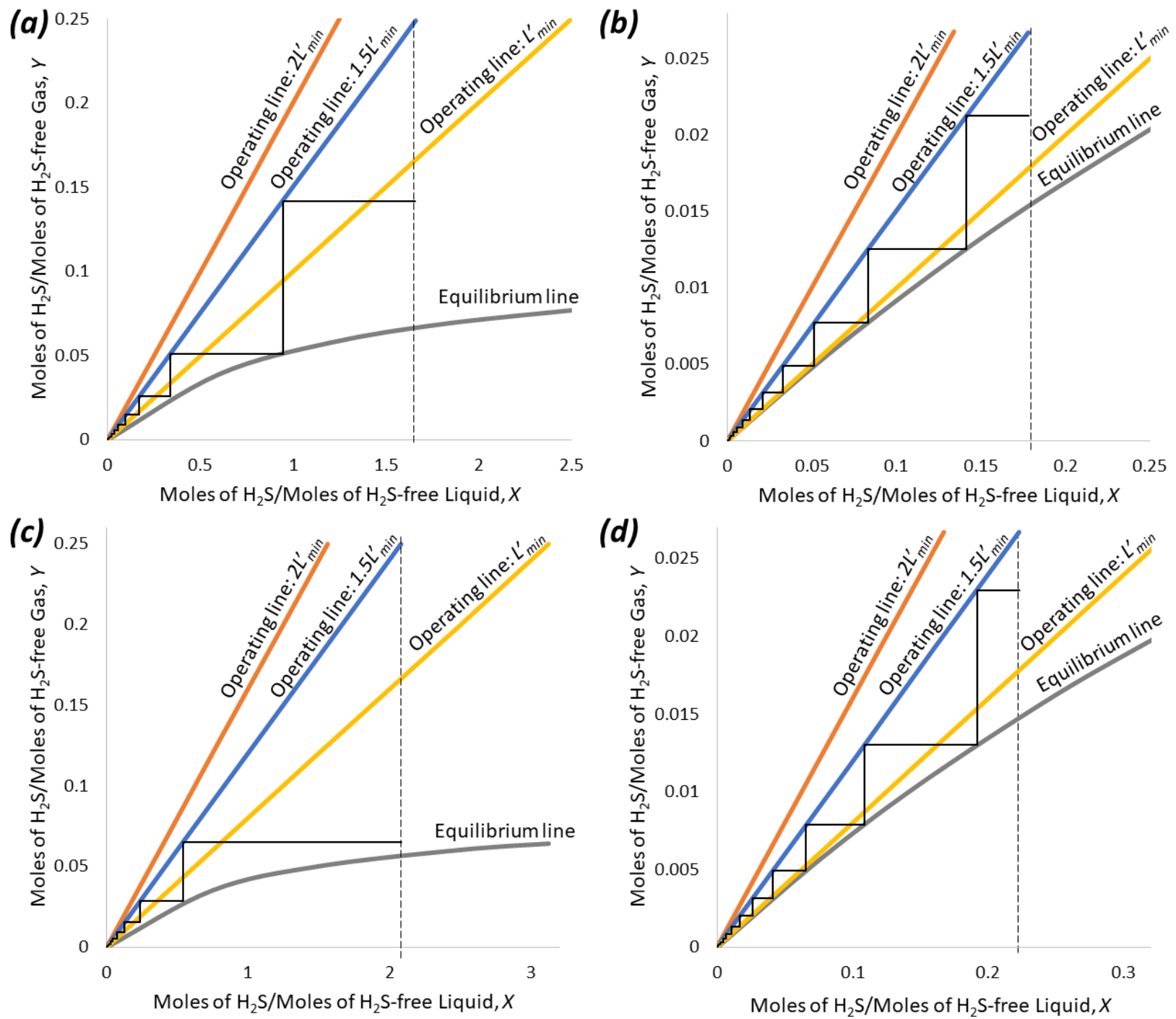

Figure 3. A graphical solution to determine the number of stages necessary for removing $99.9 \%$ of $\mathrm{H}_{2} \mathrm{~S}$ from a feed gas of (a) $20 \mathrm{~mol} \% \mathrm{H}_{2} \mathrm{~S}$ in methane, HOSBO; (b) $2.6 \mathrm{~mol}^{2} \mathrm{H}_{2} \mathrm{~S}$ in methane, HOSBO; (c) 20 $\mathrm{mol} \% \mathrm{H}_{2} \mathrm{~S}$ in methane, SBO; (d) $2.6 \mathrm{~mol} \% \mathrm{H}_{2} \mathrm{~S}$ in methane, SBO. The operating lines are based on the flow rate of the absorbent feed. The equilibrium line is based on the partition coefficient $K$ of $\mathrm{H}_{2} \mathrm{~S}$ in the absorbent, high oleic soybean oil, previously determined to be 0.1 . The graphical solution is completed for the optimum operating line of $1.5 L^{\prime}{ }_{\text {min }}$, and the number of stages $N$ was determined to be (a) 10.2 (b) 13.3 (c) 9.6 and (d) 14.2 stages.

Table 2. Optimum flow rate $\left(1.5 L^{\prime}{ }_{\text {min }}\right)$ and number of stages $(N)$ calculated for different feed conditions of $\mathrm{H}_{2} \mathrm{~S}$ (2.6 mol\% or $20 \mathrm{~mol} \%$ ) and different absorbing liquids (HOSBO or SBO) using the graphical solution method shown in Figure 3.

\begin{tabular}{|c|c|c|c|c|c|}
\hline $1.5 \mathrm{~L}_{\min }^{\prime}(\mathrm{kmol} / \mathrm{h})$ & HOSBO & SBO & $N$ & HOSBO & SBO \\
\hline $20 \mathrm{~mol}^{2} \mathrm{H}_{2} \mathrm{~S}$ & 120 & 96 & $20 \mathrm{~mol} \% \mathrm{H}_{2} \mathrm{~S}$ & 10.2 & 9.6 \\
\hline $2.6 \mathrm{~mol}^{2} \mathrm{H}_{2} \mathrm{~S}$ & 146 & 117 & $2.6 \mathrm{~mol} \% \mathrm{H}_{2} \mathrm{~S}$ & 13.3 & 14.2 \\
\hline
\end{tabular}


Additionally, the Kremser method ${ }^{7,8}$ was used to determine the amount of $\mathrm{H}_{2} \mathrm{~S}$ sorbed at each theoretical equilibrium stage $N$ using Equations 5 and 6. In Equation 5, the separation factor $(A)$ is a function of the absorbent flow rate $\left(L^{\prime}\right.$, varied from $101-250 \mathrm{kmol} / \mathrm{h}$ based on the graphical solutions), the feed gas flow rate $(V=1000 \mathrm{kmol} / \mathrm{h})$, and the partition coefficient $(K)$ of the solute $\left(\mathrm{H}_{2} \mathrm{~S}\right)$ in the system. For modeling an absorption unit, the fraction of solute absorbed can be calculated as a function of the separation factor $A$ and number of stages in the unit $N$ as shown in Equation 6.

Separation Factor

Fraction solute absorbed

$$
A=\frac{L^{\prime}}{K_{i} V}
$$

$$
\text { Fraction solute absorbed }=\frac{A^{N+1}-A}{A^{N+1}-1}
$$

Tables 3 and 4 display results for percent of solute absorbed at each stage, $N$, using 1-15 stages and varied absorbent flow rates, $L^{\prime}$. Table 3 is based on using high oleic soybean oil $(K=0.1)$ as the absorbent while Table 4 shows results for conventional soybean oil $(K=0.08)$. 
Table 3. Percent absorption of $\mathrm{H}_{2} \mathrm{~S}$ using high oleic soybean oil as the absorbent. Percent absorption of $\mathrm{H}_{2} \mathrm{~S}$ depends on the absorbent flow rate $L^{\prime}$ (varied from $\left.101-250 \mathrm{kmol} / \mathrm{h}\right)$, the partition coefficient $(K=0.1)$, feed gas flow rate $(V=1000 \mathrm{kmol} / \mathrm{h})$, and is shown for each stage $N$, up to 15 stages. The values represent the fraction of solute $\left(\mathrm{H}_{2} \mathrm{~S}\right)$ absorbed, and $\geq 99.9 \%$ is shaded green, $\geq 99.0 \%$ is shaded yellow, and $<99.0 \%$ is shaded orange. The target is greater than $99.9 \%$ absorption of the $\mathrm{H}_{2} \mathrm{~S}$.

\begin{tabular}{|c|c|c|c|c|c|c|c|c|c|c|c|c|c|c|c|}
\hline $\mathrm{nol} / \mathrm{h}$ & 1 & 2 & 3 & 4 & 5 & 6 & 7 & 8 & 9 & 10 & 11 & 12 & 13 & 14 & 15 \\
\hline 101 & $50.2 \%$ & $67.0 \%$ & $75.4 \%$ & $80.4 \%$ & $83.7 \%$ & $86.1 \%$ & $87.9 \%$ & $89.3 \%$ & $90.4 \%$ & $91.4 \%$ & $92.1 \%$ & $92.8 \%$ & $93.3 \%$ & $93.8 \%$ & $94.2 \%$ \\
\hline 125 & $55.6 \%$ & $73.8 \%$ & $82.7 \%$ & $87.8 \%$ & $91.1 \%$ & $93.4 \%$ & $95.0 \%$ & $96.1 \%$ & $97.0 \%$ & $97.7 \%$ & $98.2 \%$ & $98.5 \%$ & $98.8 \%$ & $99.1 \%$ & $99.3 \%$ \\
\hline 146 & $59.3 \%$ & $78.2 \%$ & $87.0 \%$ & $91.8 \%$ & $94.7 \%$ & $96.5 \%$ & $97.7 \%$ & $98.4 \%$ & $98.9 \%$ & $99.3 \%$ & $99.5 \%$ & $99.7 \%$ & $99.8 \%$ & $99.8 \%$ & $99.9 \%$ \\
\hline 175 & $63.6 \%$ & $82.8 \%$ & $91.0 \%$ & $95.1 \%$ & $97.3 \%$ & $98.5 \%$ & $99.1 \%$ & $99.5 \%$ & $99.7 \%$ & $99.8 \%$ & $99.9 \%$ & $99.9 \%$ & $100.0 \%$ & $100.0 \%$ & $100.0 \%$ \\
\hline 200 & $66.7 \%$ & $85.7 \%$ & $93.3 \%$ & $96.8 \%$ & $98.4 \%$ & $99.2 \%$ & $99.6 \%$ & $99.8 \%$ & $99.9 \%$ & $100.0 \%$ & $100.0 \%$ & $100.0 \%$ & $100.0 \%$ & $100.0 \%$ & $100.0 \%$ \\
\hline 225 & $69.2 \%$ & $88.0 \%$ & $94.9 \%$ & $97.8 \%$ & $99.0 \%$ & $99.6 \%$ & $99.8 \%$ & $99.9 \%$ & $100.0 \%$ & $100.0 \%$ & $100.0 \%$ & $100.0 \%$ & $100.0 \%$ & $100.0 \%$ & $100.0 \%$ \\
\hline 250 & $71.4 \%$ & $89.7 \%$ & $96.1 \%$ & $98.4 \%$ & $99.4 \%$ & $99.8 \%$ & $99.9 \%$ & $100.0 \%$ & $100.0 \%$ & $100.0 \%$ & $100.0 \%$ & $100.0 \%$ & $100.0 \%$ & $100.0 \%$ & $100.0 \%$ \\
\hline
\end{tabular}

Table 4. Percent absorption of $\mathrm{H}_{2} \mathrm{~S}$ using conventional soybean oil as the absorbent. Percent absorption of $\mathrm{H}_{2} \mathrm{~S}$ depends on the absorbent flow rate $L^{\prime}$ (varied from $\left.101-250 \mathrm{kmol} / \mathrm{h}\right)$, the partition coefficient $(K=$ $0.1)$, feed gas flow rate $(V=1000 \mathrm{kmol} / \mathrm{h})$, and is shown for each stage $N$, up to 15 stages. The values represent the fraction of solute $\left(\mathrm{H}_{2} \mathrm{~S}\right)$ absorbed, and $\geq 99.9 \%$ is shaded green, $\geq 99.0 \%$ is shaded yellow, and $<99.0 \%$ is shaded orange. The target is greater than $99.9 \%$ absorption of the $\mathrm{H}_{2} \mathrm{~S}$.

\begin{tabular}{|c|c|c|c|c|c|c|c|c|c|c|c|c|c|c|c|}
\hline $\mathrm{mol} / \mathrm{h}$ & 1 & 2 & 3 & 4 & 5 & 6 & 7 & 8 & 9 & 10 & 11 & 12 & 13 & 14 & 15 \\
\hline 96 & $54.5 \%$ & $72.5 \%$ & $81.4 \%$ & $86.6 \%$ & $89.9 \%$ & $92.3 \%$ & $93.9 \%$ & $95.2 \%$ & $96.1 \%$ & $96.9 \%$ & $97.5 \%$ & $97.9 \%$ & $98.3 \%$ & $98.6 \%$ & $98.9 \%$ \\
\hline 101 & $55.8 \%$ & $74.1 \%$ & $83.0 \%$ & $88.1 \%$ & $91.4 \%$ & $93.6 \%$ & $95.2 \%$ & $96.3 \%$ & $97.2 \%$ & $97.8 \%$ & $98.3 \%$ & $98.7 \%$ & $99.0 \%$ & $99.2 \%$ & $99.4 \%$ \\
\hline 117 & $59.4 \%$ & $78.3 \%$ & $87.1 \%$ & $91.9 \%$ & $94.7 \%$ & $96.5 \%$ & $97.7 \%$ & $98.4 \%$ & $98.9 \%$ & $99.3 \%$ & $99.5 \%$ & $99.7 \%$ & $99.8 \%$ & $99.8 \%$ & $99.9 \%$ \\
\hline 125 & $61.0 \%$ & $80.0 \%$ & $88.7 \%$ & $93.2 \%$ & $95.8 \%$ & $97.4 \%$ & $98.4 \%$ & $99.0 \%$ & $99.3 \%$ & $99.6 \%$ & $99.7 \%$ & $99.8 \%$ & $99.9 \%$ & $99.9 \%$ & $100.0 \%$ \\
\hline 156 & $66.1 \%$ & $85.2 \%$ & $92.9 \%$ & $96.5 \%$ & $98.2 \%$ & $99.1 \%$ & $99.5 \%$ & $99.8 \%$ & $99.9 \%$ & $99.9 \%$ & $100.0 \%$ & $100.0 \%$ & $100.0 \%$ & $100.0 \%$ & $100.0 \%$ \\
\hline 200 & $71.4 \%$ & $89.7 \%$ & $96.1 \%$ & $98.4 \%$ & $99.4 \%$ & $99.8 \%$ & $99.9 \%$ & $100.0 \%$ & $100.0 \%$ & $100.0 \%$ & $100.0 \%$ & $100.0 \%$ & $100.0 \%$ & $100.0 \%$ & $100.0 \%$ \\
\hline 250 & $75.8 \%$ & $92.8 \%$ & $97.7 \%$ & $99.3 \%$ & $99.8 \%$ & $99.9 \%$ & $100.0 \%$ & $100.0 \%$ & $100.0 \%$ & $100.0 \%$ & $100.0 \%$ & $100.0 \%$ & $100.0 \%$ & $100.0 \%$ & $100.0 \%$ \\
\hline
\end{tabular}

The graphical solution indicated $146 \mathrm{kmol} / \mathrm{h}$ would be an optimal absorbent feed flow rate when using high oleic soybean oil. Using the Kremser method, it is evident that as absorbent flow rate increases, the number of stages required to attain $99.9 \%$ absorption of $\mathrm{H}_{2} \mathrm{~S}$ decreases. However, 
there may be other negative impacts of increasing solvent flow rate, such as increased solvent use and solvent cost.

Another way of examining the system is to set a flow rate and compare the amount of $\mathrm{H}_{2} \mathrm{~S}$ absorbed by the different absorbing bio-oils. In this method, the absorbent flow rate $(L)$, feed gas flow rate ( $V$ ) are fixed and the absorption factor $A$ is dependent on the $K$ value of $\mathrm{H}_{2} \mathrm{~S}$ in each bio-oil. Figure 4 shows the comparison between the bio-oil absorption capacity at different equilibrium stages for two absorbent flow rates, $125 \mathrm{kmol} / \mathrm{h}$ and $200 \mathrm{kmol} / \mathrm{h}$.
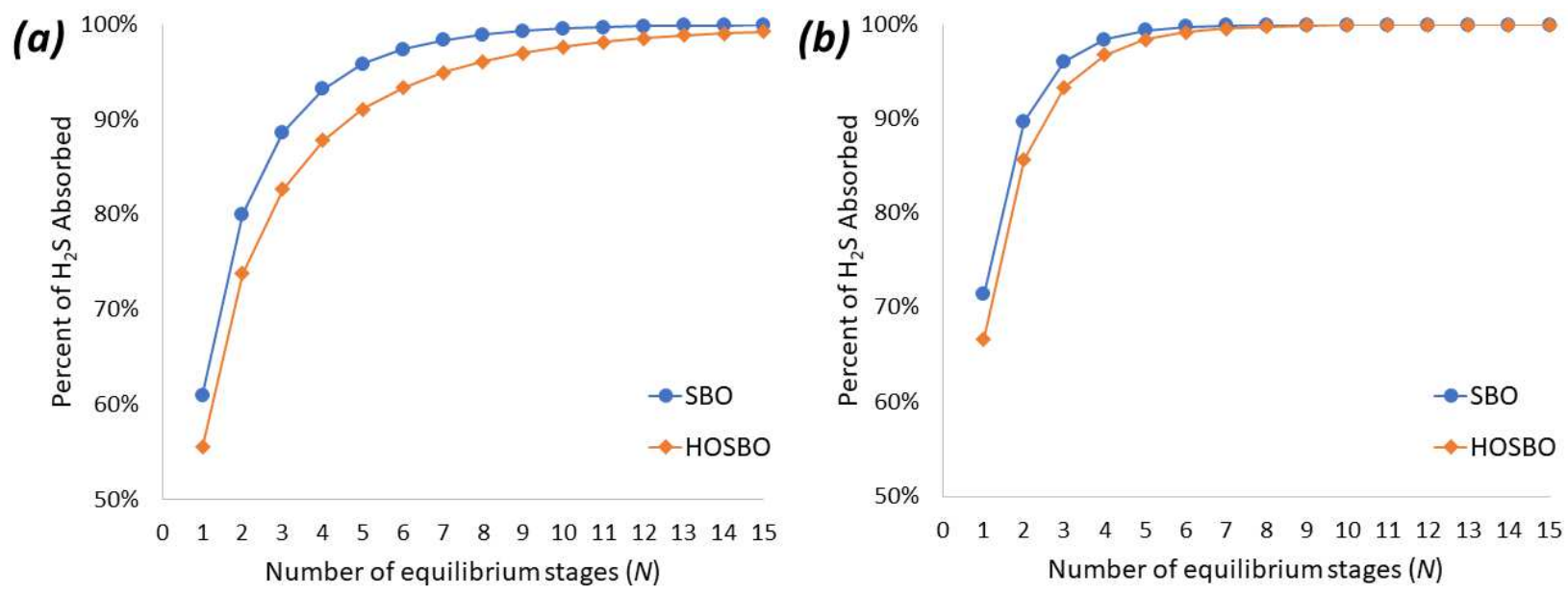

Figure 4. The percent of $\mathrm{H}_{2} \mathrm{~S}$ recovered at each equilibrium stage is dependent by each oil at absorbent flow rates (L) of (a) $125 \mathrm{kmol} / \mathrm{h}$ and (b) $200 \mathrm{kmol} / \mathrm{h}$. The percent of $\mathrm{H}_{2} \mathrm{~S}$ recovered is a function of the absorbent flow rate, the feed gas flow rate $(\mathrm{V}=1000 \mathrm{kmol} / \mathrm{h})$, and the $\mathrm{K}$ value for $\mathrm{H}_{2} \mathrm{~S}$ in each oil $(0.08$ for SBO, 0.1 for HOSBO), as shown in Equations 5 and 6.

As seen in Figure 4 and in Tables 3 and 4, each oil is capable of attaining $99.9 \% \mathrm{H}_{2} \mathrm{~S}$ absorption after some number of stages, $N$. In the case of the lower flow rate, as shown in Figure 4a, the difference between the oils is larger (root mean square deviation is 0.037 ) while requiring 14 stages for both oils to achieve $>99.0 \% \mathrm{H}_{2} \mathrm{~S}$ sorption. At a higher flow rate (Figure $4 \mathrm{~b}$ ), the oils' $\mathrm{H}_{2} \mathrm{~S}$ absorption more quickly converges (root mean square deviation is 0.018 ) and only five stages are required to attain $>99.0 \%$ sorption of $\mathrm{H}_{2} \mathrm{~S}$. A balance must be struck between number of stages, optimal flow rate, and the resulting bio-oil solvent use. For the remaining analysis, an absorbent 
flow rate of $120 \mathrm{kmol} / \mathrm{h}$ soybean oil was chosen to limit solvent use while attaining $99.9 \%$ removal of $\mathrm{H}_{2} \mathrm{~S}$ in the least number of stages.

\section{Column Design and Capital Costs}

A significant cost of developing a natural gas processing facility that used bio-oils as the absorbing solvent would be the cost of the absorption unit. Based on the flow rates determined in the previous section (1000 kmol/h feed gas flow rate; $120 \mathrm{kmol} / \mathrm{h}$ bio-oil solvent flow rate) and the size and daily processing needs of existing gas treatment methods like amine gas treating, a sieve-plate tray column is recommended as the absorption unit. Other cost considerations would include piping, installation, and any other units for solvent storage, etc.

To design an extraction column to meet the needs for $1000 \mathrm{kmol} / \mathrm{h}$ of feed gas, $120 \mathrm{kmol} / \mathrm{h}$ of liquid absorbent, and 14 trays (determined by the equilibrium stage calculations: Equations 1-6; Figures 3-4; Tables 3-4), flooding capacity of the column must be calculated.

Flooding capacity is a function of the density of the liquid and vapor phases and a flooding capacity factor, $C$. Equations $7-12$ were used to characterize column flooding capacity. Equations 7-12 were solved sequentially. Equation 7 - for the entrainment flooding capacity $\left(F_{L V}\right)$ was first. In Equation 7, $L$ and $V$ are the liquid and vapor feed flow rates respectively, $M_{L}$ and $M_{V}$ are the molar masses of the liquid and vapor, and $\rho_{L}$ is the liquid density and $\rho_{V}$ is the vapor density. The entrainment flooding capacity $\left(F_{L V}\right)$ is then used to solve Equation 8, to find the ratio of the active tray area $\left(A_{d}\right)$ to the total tray area $(A)$. This ratio from Equation 8 is then used to solve Equation 9 and find the factor for ratio of vapor hole area to tray active area. Next, Equation 10 was used to find the surface tension factor, $F_{S T}$, which is a function of the surface tension of the liquid, $\sigma$. Having solved equations 7-10, Equation 11 for the flooding capacity parameter, $C$, can be solved. In Equation 11, $C$ is the flooding capacity parameter, $F_{S T}$ is the surface tension factor solved for in 
Equation $10, F_{F}$ is a foaming factor assumed to be $1.0, F_{H A}$ is the factor for ratio of vapor hole area to tray active area from Equation 9, and $C_{F}$ can be graphically estimated as a function of $F_{L V}$ and plate height, which in this case was assumed to be 24 inches and gave a $C_{F}$ of $0.35 .{ }^{7,9}$ Finally, Equation 12 for flooding velocity is solved. Flooding velocity, $U_{f}$, is a function of the flooding capacity parameter, $C$ (Equation 11), and the liquid density, $\rho_{L}$, and the vapor density, $\rho_{V}$. Table 5 shows the parameters used in Equations 7-12.

$\begin{aligned} & \text { Entrainment flooding } \\ & \text { capacity }, 9\end{aligned} \quad F_{L V}=\left(\frac{L M_{L}}{V M_{V}}\right)\left(\frac{\rho_{V}}{\rho_{L}}\right)^{0.5}$

Ratio of active tray area $\left(A_{d}\right) \quad \frac{A_{d}}{A}=0.1+\frac{\left(F_{L V}-0.1\right)}{9}, 0.1 \leq F_{L V} \leq 1.0$
to total tray area $(A)^{7,9}$

Factor for ratio of vapor hole area to tray active area

$$
\begin{gathered}
F_{H A}=1.0 \text { for } A_{d} / A_{a} \geq 0.10 \\
F_{H A}=5\left(A_{d} / A_{a}\right)+0.5 \text { for } 0.06 \geq A_{d} / A_{a} \leq 0.1 \\
F_{S T}=\left(\frac{\sigma}{20}\right)^{0.2} \\
C=F_{S T} F_{F} F_{H A} C_{F} \\
U_{f}=C\left(\frac{\rho_{L}-\rho_{V}}{\rho_{V}}\right)^{0.5}
\end{gathered}
$$$$
\text { Flooding Velocity }{ }^{7}
$$ 
Table 5. Parameters used in tray diameter and flooding capacity calculations for design of an absorption column.

\begin{tabular}{|c|c|c|}
\hline Parameter & Parameter Value & Source (if applicable) \\
\hline Temperature & $298 \mathrm{~K}$ & \\
\hline Pressure & $110 \mathrm{kPa}$ & - \\
\hline$V$, vapor flow rate & $1000 \mathrm{kmol} / \mathrm{h}$ & - \\
\hline$L$, liquid flow rate & $120 \mathrm{kmol} / \mathrm{h}$ & - \\
\hline $\begin{array}{l}M_{V}, \text { molecular weight of vapor } \\
\text { phase with } 20 \% \mathrm{H}_{2} \mathrm{~S} \text { and } 80 \% \mathrm{CH}_{4}\end{array}$ & $32.4 \mathrm{~kg} / \mathrm{kmol}$ & $\begin{array}{r}\text { Calculated based on feed gas } \\
\text { composition }\end{array}$ \\
\hline $\begin{array}{l}M_{L}, \text { molecular weight of soybean } \\
\text { oil }\end{array}$ & $920 \mathrm{~kg} / \mathrm{kmol}$ & Patzek $2009^{10}$ \\
\hline $\begin{array}{l}\rho_{L} \text {, density of vapor phase with } \\
20 \% \mathrm{H}_{2} \mathrm{~S} \text { and } 80 \% \mathrm{CH}_{4}\end{array}$ & $1.438 \mathrm{~kg} / \mathrm{m}^{3}$ & $\begin{array}{r}\text { Calculated using ideal gas } \\
\text { law }\end{array}$ \\
\hline$\rho_{L}$, density of soybean oil & $916 \mathrm{~kg} / \mathrm{m}^{3}$ & Sahasrabudhe et al. $2017^{11}$ \\
\hline$F_{F}$, foaming factor & 1.0 & Seader \& Henley, $1998^{7}$ \\
\hline$\sigma$, surface tension & 29.4 dynes/cm & Sahasrabudhe et al. $2017^{11}$ \\
\hline Tray height & 24 inches & - \\
\hline$f$, flooding capacity & 0.8 & - \\
\hline
\end{tabular}

Equations 7-12 must be solved prior to calculating the required column diameter since column diameter is a function of flooding velocity, flooding capacity, surface tension and active tray area. Ultimately, column diameter $\left(D_{T}\right)$ can be calculated using Equation 13 as a function of the gas flow rate $(V)$ and molar mass $\left(M_{V}\right)$, the flooding velocity $\left(U_{f}\right)$ multiplied by a flooding factor $(f)$, ratio of tray active area to area $\left(A_{d} / A\right)$ and the density of the vapor phase $\left(\rho_{v}\right)$. For Equation 13, $V$, $M_{V}$, and $\rho_{V}$ are all given in Table 5. $A_{d} / A$ was calculated using Equation 11, and $U_{f}$ was calculated using Equation 7. The flooding capacity $f$ must be chosen based on desired column performance. A good rule of thumb is that flooding capacity is often best around 60\%, but anywhere from 40$90 \%$ is reasonable. ${ }^{7}$ In this case, $f=0.8$ is used, as that is reasonable for a gas absorption column and will help keep the column size smaller, which keeps costs lower. ${ }^{7}$ 
Column diameter

$$
D_{T}=\left[\frac{4 V M_{V}}{f U_{f} \pi\left(1-\frac{A_{d}}{A}\right) \rho_{V}}\right]^{0.5}
$$

Finally, column diameter was calculated as $1.96 \mathrm{~m}$ or $6.39 \mathrm{ft}$; for 14 trays and 24 inches between each tray, column height would be $28 \mathrm{ft}$. Using a column diameter of $2 \mathrm{~m}$ and column height of $8.5 \mathrm{~m}(6.4 \mathrm{ft}$ and $28 \mathrm{ft})$, the total column volume would be $84.2 \mathrm{~m}^{3}$.

Equation 14 relates the cost of a carbon steel trayed column $\left(C_{P}^{0}\right)$ to a column size attribute $(A$, volume in $\mathrm{m}^{3}$ ) and three constants, $K_{1}, K_{2}$, and $K_{3} .{ }^{12}$ The constants are obtained from Turton et al. 2012 Table A- $1 .{ }^{12} K_{l}=3.4974, K_{2}=0.4485, K_{3}=0.1074$, and $A=84.2 \mathrm{~m}^{3}$.

$$
\begin{array}{lc}
\text { Equipment Cost Equation } & \log C_{P}^{0}=K_{1}+K_{2} \log (A)+K_{3}[\log (A)]^{2} \\
\text { Cost Index Adjustment } & C_{2}=C_{1}\left(\frac{I_{2}}{I_{1}}\right)
\end{array}
$$

However, Equation 14 is normalized for material pricing in 2001. To obtain an estimate for current pricing, a cost adjustment using the Chemical Engineering Plant Cost Index (CEPCI) was used. In Equation 15, the 2019 cost $\left(C_{2}\right)$ is equal to the 2001 cost $\left(C_{1}=C_{P}^{0}\right.$ from Equation 14$)$ multiplied by the ratio of the 2019 CEPCI $\left(I_{2}=607.5\right)$ to the 2001 CEPCI $\left(I_{1}=394\right) .{ }^{12,13}$ The cost of the extraction column, with the desired specifications, is estimated at $\$ 131,600$.

\section{Solvent Cost}

Regeneration of the solvent (soybean or high oleic soybean oil) will be critical to lowering operating costs and developing the present method into a viable process that can compete economically with amine gas treating. The upper acceptable limit for the cost of regeneration will be explored in this discussion. Examining annual solvent cost as a function of the percent of solvent that is regenerated and recycled gives insight into the viability of using bio-oils as extraction 
solvents. Soybean oil is examined as a case study representative of similar costs and trends with other bio-oils.

Soybean oil availability is dependent on soybeans harvested, and about 10\% (by mass) of soybeans harvested is converted into soybean oil, annually, as shown in Figure 5. Soybean oil accounts for $55 \%$ of vegetable oil consumption in the United States, with canola oil taking $14 \%$ of the market share and other vegetable oils taking less than $10 \%$ each. ${ }^{14} 68 \%$ of soybean oil is used in food products, $25 \%$ in biodiesel and for bioheat, and $7 \%$ goes to industrial uses including solvents, paints, plastics and cleaners. ${ }^{14}$ The U.S. Soybean Check-off advertises a "Fuel vs. Food: You don’t have to choose" message, indicating a national effort to find new industrial and non-food uses of soybean oils. ${ }^{15}$ Soybean oil prices are shown in Figure 6.

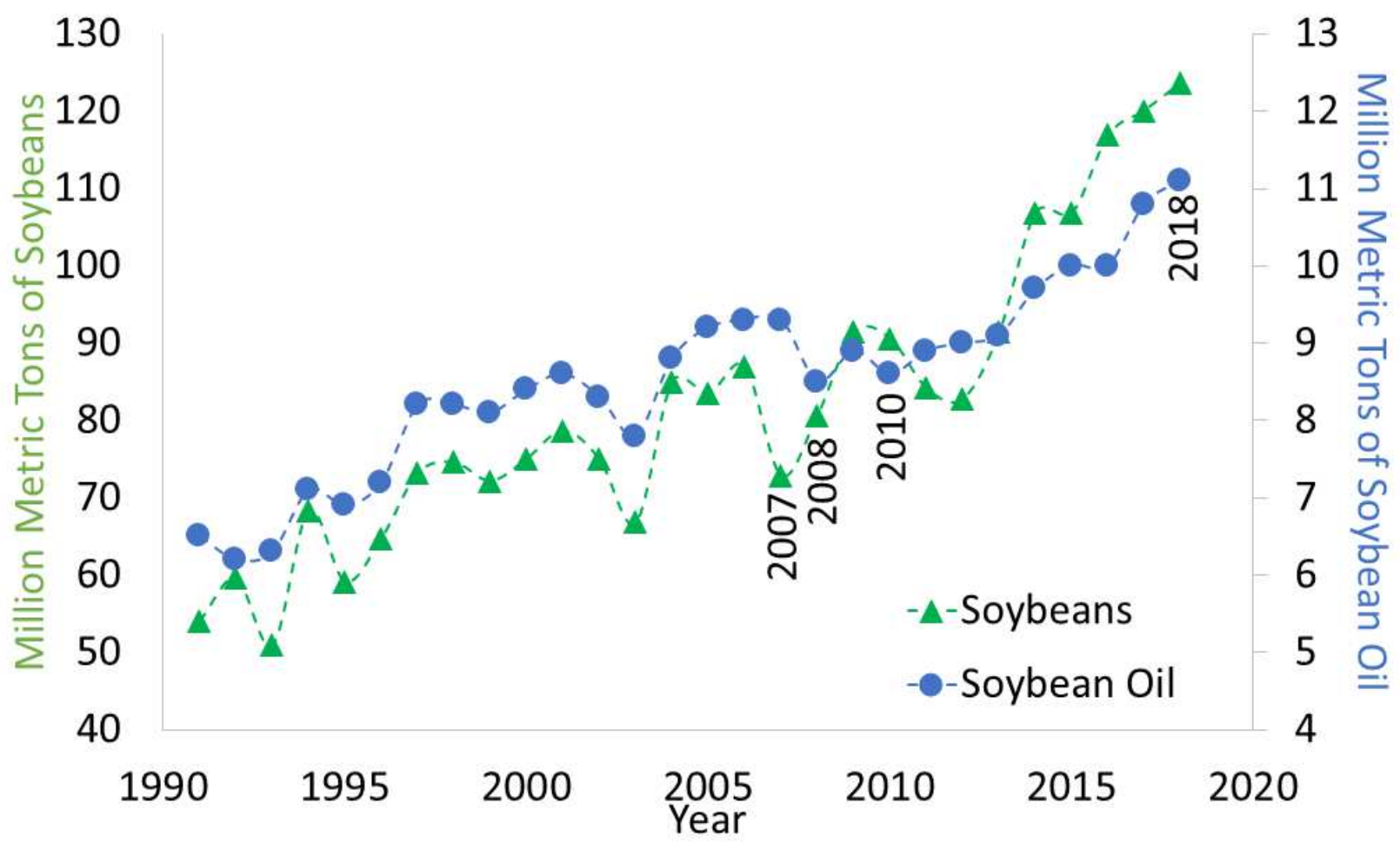

Figure 5. Soybean and soybean oil production in the United States, 1991 - 2018. Soybean oil production is about $10 \%$ (by mass) of soybean production overall and has continued to rise from 2010 - present. 


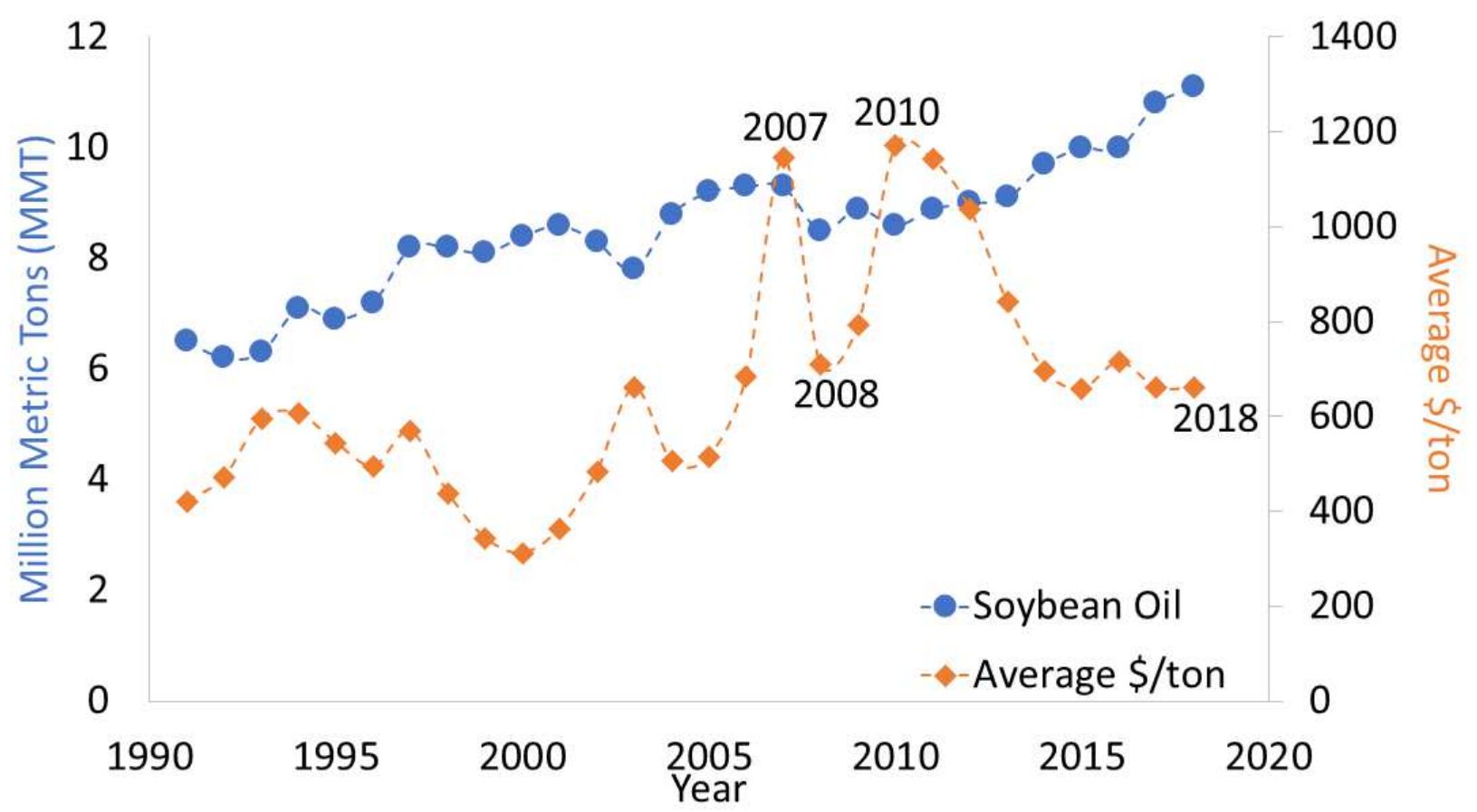

Figure 6. U.S. Soybean oil production and prices from $1991-2018$.

On average from $2014-2018$, the price of one metric ton of soybean oil was $\$ 679$, with yearly prices shown in Table 6. Natural gas plants typically operate year-round with $5-10 \%$ of forced downtime for maintenance and outages, both scheduled and unscheduled. ${ }^{16}$ Figure 7 shows the solvent cost in millions of U.S. dollars per year, depending on if the absorption unit is operating continuously or if the plant anticipates $5-10 \%$ of the year that the absorption unit would be offline and solvent would not be required. The price is based on the $2014-2018$ average of $\$ 679 /$ metric ton of soybean oil but could increase in future years.

Table 6. U.S. soybean oil production and average \$/ton of soybean oil from $2014-2018$. The five-year average is $\$ 679 /$ metric ton of soybean oil.

\begin{tabular}{ccc}
\hline Year & $\begin{array}{c}\text { Soybean Oil } \\
\text { (Million Metric Tons) }\end{array}$ & $\begin{array}{c}\text { Average } \mathbf{\$} / \text { ton of } \\
\text { soybean oil }\end{array}$ \\
\hline 2014 & 9.7 & $\$ 697$ \\
2015 & 10.0 & $\$ 659$ \\
2016 & 10.0 & $\$ 716$ \\
2017 & 10.8 & $\$ 661$ \\
2018 & 11.1 & $\$ 661$ \\
\hline
\end{tabular}




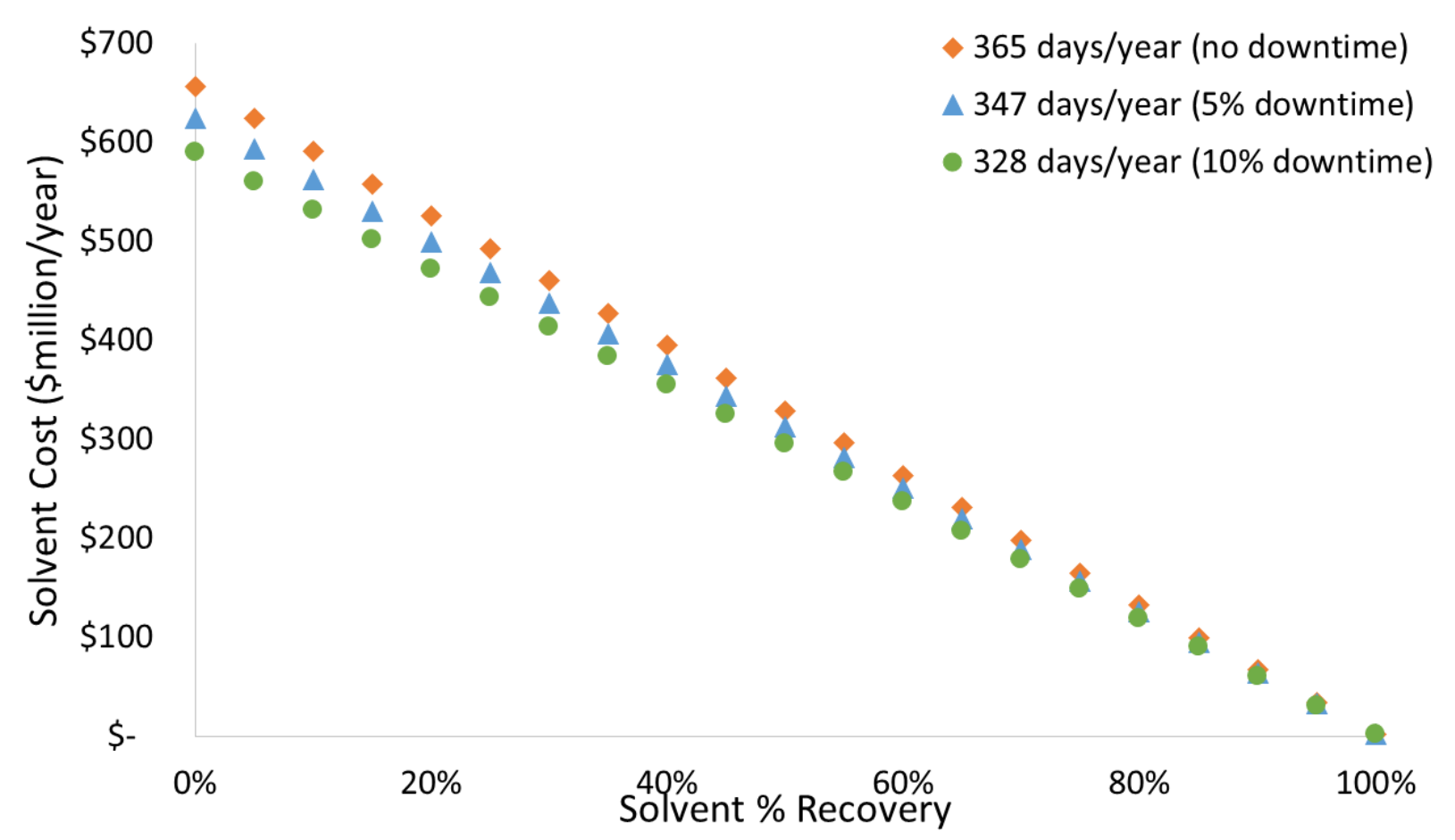

Figure 7. Solvent cost of using soybean oil (\$679/ton) depending on the amount of solvent that can be recovered and re-used, and the anticipated downtime of the absorption unit of the plant. For a plant operating $95 \%$ of the year, solvent cost with no recovery would amount to $\$ 624$ million/year, but even $50 \%$ of solvent recovery would result in a solvent cost of $\$ 312$ million/year.

\section{Adding Value through Sulfur Recovery}

In addition to post-absorption recovery of $\mathrm{H}_{2} \mathrm{~S}$, which would require the bio-oil solvents to be regenerated and recycled, conversion of $\mathrm{H}_{2} \mathrm{~S}$ to elemental sulfur would allow for sulfur to be a secondary product of the process and generate revenue. Sulfur is a valuable chemical building block used to make sulfuric acid and other commodity chemicals and products. The annual demand for sulfur in the United States exceeds 12.7 megatons, and $36 \%$ of that is imported annually. ${ }^{6}$ The current selling price of sulfur is around $\$ 200 /$ ton, and has remained stable above $\$ 150 /$ ton since $2014 .^{6}$

A relationship can be developed to predict the revenue generated in recovering and selling sulfur. This relationship is based on the selling price of sulfur (\$200/ton), the amount of sulfur recovered out of the potential amount of sulfur recovered (assumed 90\%), portion of the year the plant is 
online $(90-100 \%$ of the year, assuming the absorption is running at full capacity for all the time online), and the feed gas concentration of $\mathrm{H}_{2} \mathrm{~S}$. This relationship is displayed in Figure 8 .

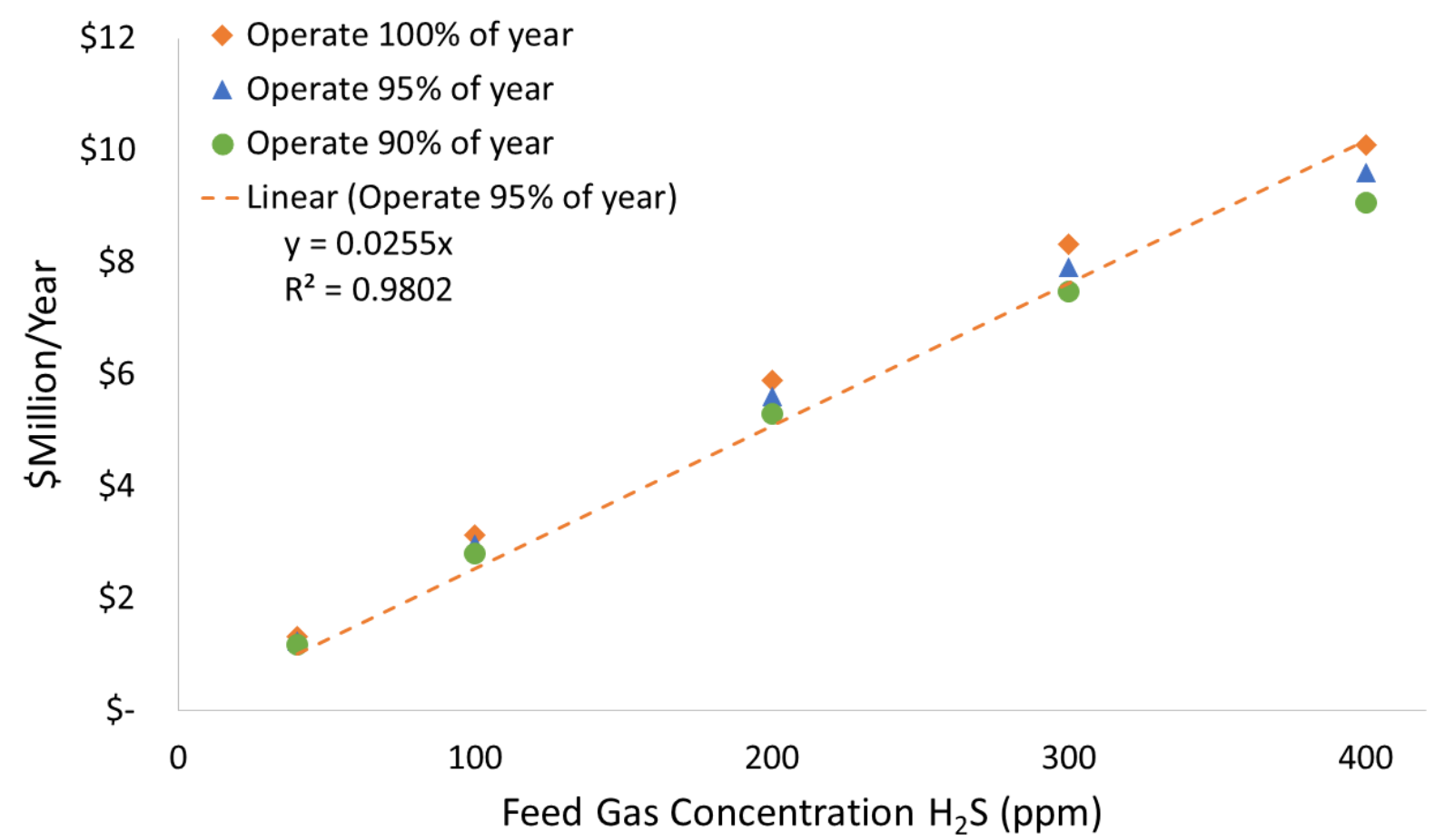

Figure 8. Assuming that $90 \%$ of all $\mathrm{H}_{2} \mathrm{~S}$ processed is successfully captured and converted to sulfur, revenues from $\$ 1.2$ - $\$ 10$ million annually can be anticipated from sulfur sales. This is dependent on the concentration of $\mathrm{H}_{2} \mathrm{~S}$ in the feed gas being processed throughout the year, as well as the portion of the year the plant is online and operating (assuming the absorption unit is at full capacity and online for the same percent of the year as the plant). Processing more sour gas (400 ppm) would lead to higher revenues than less sour gas (40 ppm). If the plant and absorption unit are online and full capacity $95 \%$ of the year, and the average feed gas concentration for the year was $200 \mathrm{ppm}_{2} \mathrm{~S}$, an annual revenue of approximately $\$ 5.6$ million could be expected. This would correspond to selling 28,000 tons of sulfur per year.

The $\mathrm{H}_{2} \mathrm{~S}$ recovered from the natural gas must be captured and harnessed in some way, as regulations prevent the emission of this hazardous gas to the atmosphere. ${ }^{2,6}$ Conversion to sulfur for sale as a chemical building block is a potential lucrative option, and the Claus process for converting gaseous $\mathrm{H}_{2} \mathrm{~S}$ to elemental sulfur is well established. ${ }^{17,18}$ 


\section{Determination of the upper limit for the cost of solvent regeneration}

The amount of $\mathrm{CH}_{4}$ available will be higher when the concentration of $\mathrm{H}_{2} \mathrm{~S}$ is lower, as shown in

Figure 9. The most recent price for industrial natural gas is $\$ 3.54 /$ thousand $\mathrm{ft}^{3}$ as of February $2020^{19}$ and is used for the revenue calculations shown in Figure 9, assuming that the absorption unit is able to process $1000 \mathrm{kmol} / \mathrm{h}$ of natural gas when online, and that $100 \%$ of the $\mathrm{CH}_{4}$ in the feed gas is recovered.

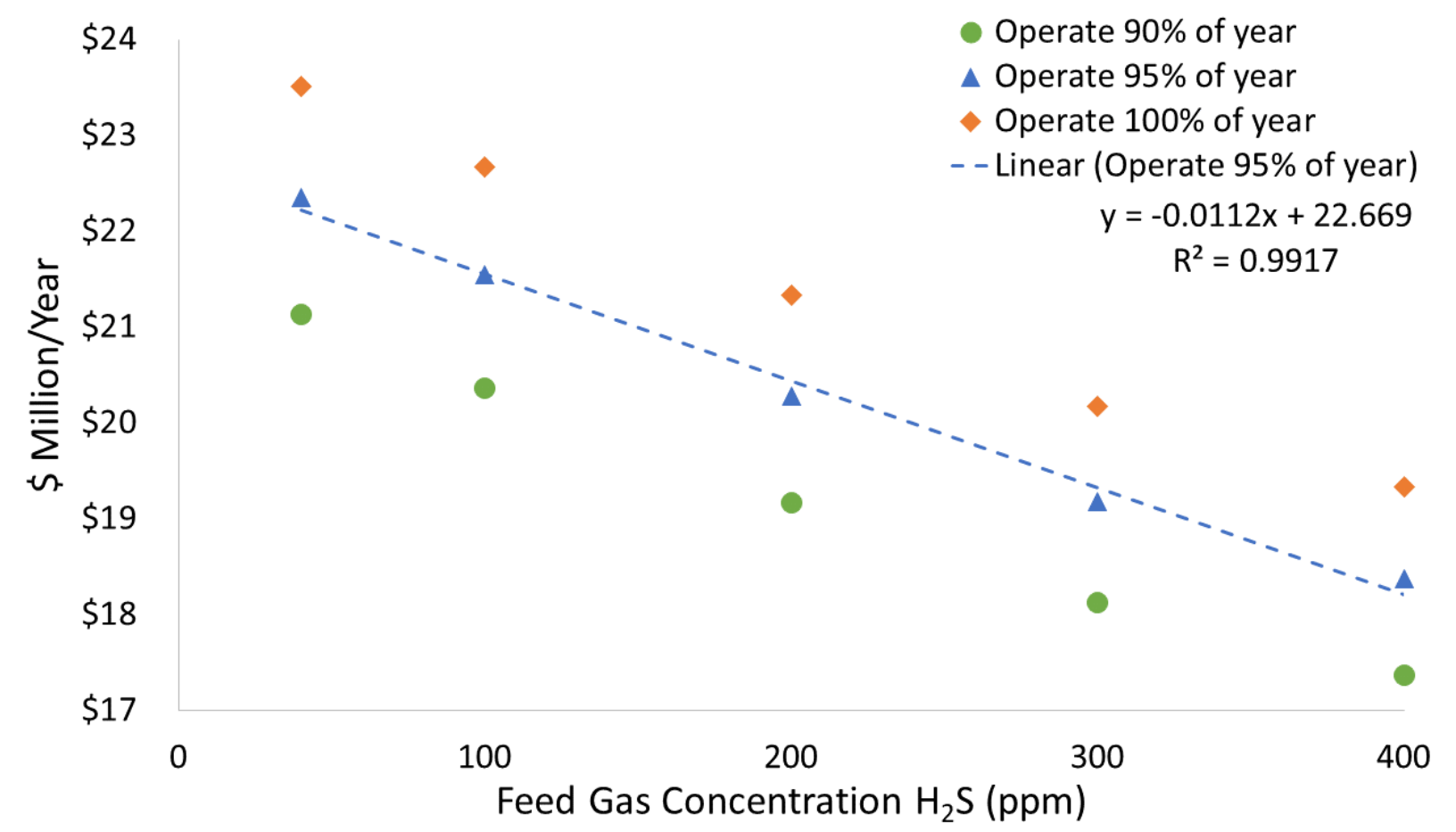

Figure 9. Annual revenue from processing natural gas.

However, a more sour gas gives less $\mathrm{CH}_{4}$ but more $\mathrm{H}_{2} \mathrm{~S}$, and overall it is more profitable to process a more sour gas (Figure 10). Even as the amount of near-pure methane recovered decreases, the increased recovery of sulfur makes up for the loss and in fact is more valuable. 


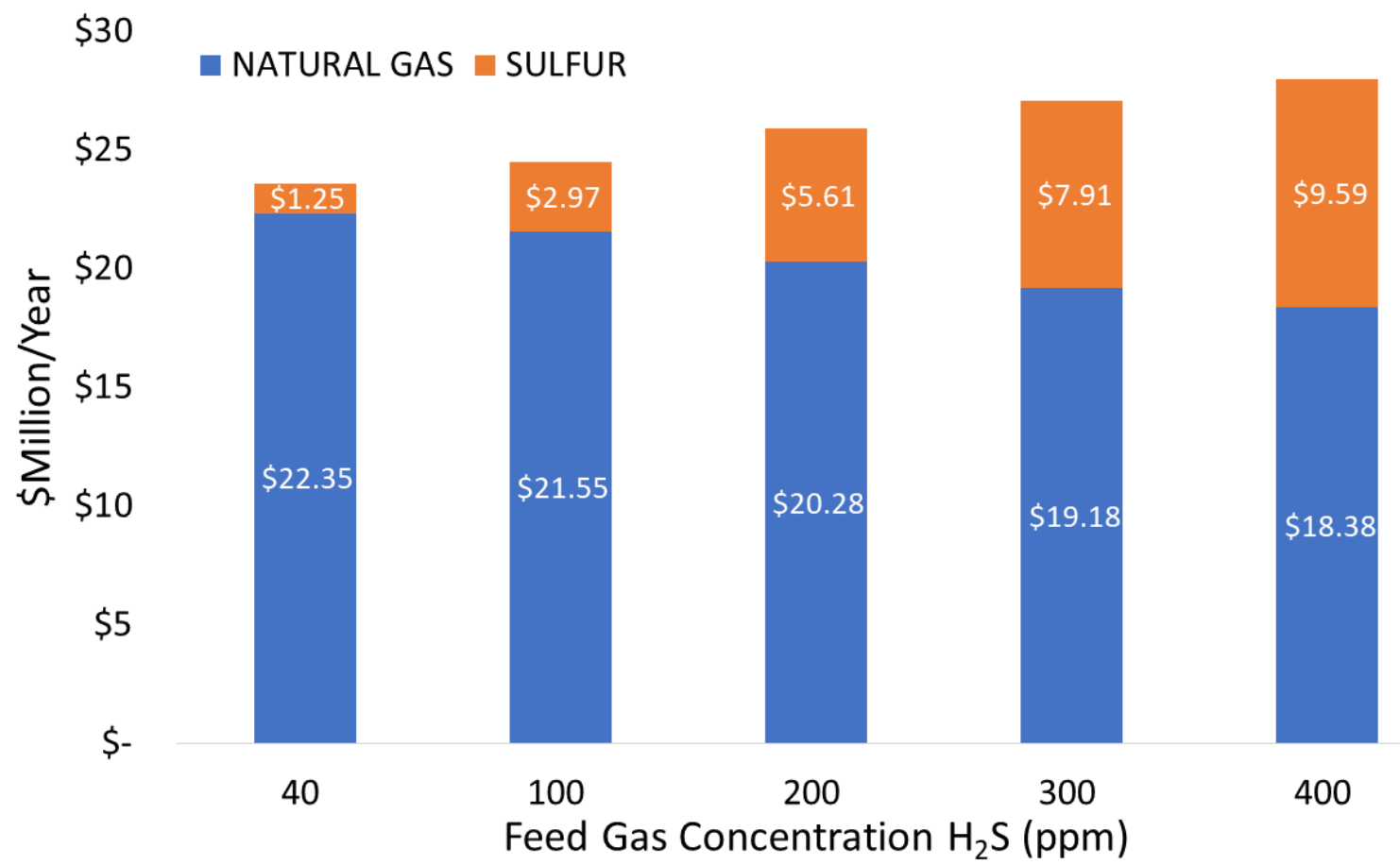

Figure 10. Revenue generated by the designed absorption unit operating with $5 \%$ downtime annually, $100 \%$ recovery of $\mathrm{CH}_{4}$, and $90 \%$ recovery and conversion of $\mathrm{H}_{2} \mathrm{~S}$ to elemental sulfur. As feed gas becomes increasingly sour, although amount of sweet gas for sale will decrease, sales of sulfur will increase and increase the total revenue.

Based on $1000 \mathrm{kmol} / \mathrm{h}$ gas entering the extraction column, 5\% downtime annually (but otherwise at full capacity), an average feed gas concentration of $200 \mathrm{ppm} \mathrm{H}_{2} \mathrm{~S}$ (with $90 \%$ sulfur recovery and $100 \% \mathrm{CH}_{4}$ recovery), and 100\% solvent regenerated, costs and revenues are shown in Table 7.

Table 7. Costs and projected revenues for the designed absorption unit processing $1000 \mathrm{kmol} / \mathrm{h}$ gas with $5 \%$ downtime annually, an average feed gas concentration of $200 \mathrm{ppm}$, with $100 \%$ recovery of $\mathrm{CH} 4$ (primary sweet gas component) and $90 \%$ recovery and conversion of $\mathrm{H}_{2} \mathrm{~S}$ to elemental sulfur. The known costs can be used to set a limit for regeneration of the bio-solvent and precipitation of sulfur to stay competitive with other methods.

\begin{tabular}{llll}
\hline & \multicolumn{2}{l}{ Sources } & Amount \\
\hline \multirow{3}{*}{ Costs } & Fixed & Extraction Column & $\$ 131,600$ \\
\cline { 2 - 4 } & Variable & Extraction Solvent & $\$ 8,000,000 /$ year \\
\cline { 2 - 4 } & Fixed & Regeneration/Precipitation Unit(s) & TBD \\
\hline \multirow{2}{*}{ Revenues } & Sweetened natural gas & $\$ 20,280,000 /$ year \\
\cline { 2 - 3 } & Sulfur & $\$ 5,610,000 /$ year \\
\hline
\end{tabular}


Total profits for the plant will be revenue from selling sulfur and sweet gas minus the fixed costs of capital investments, maintenance and operating costs. While the cost of the extraction column was estimated here, the maximum cost of a regeneration/precipitation unit is to be determined, there may be other costs for heat exchangers, reboilers and condensers, and other installation parts. Bryan Research \& Engineering found that the absorption and stripping columns of amine gas treatment facilities typically comprise less than $45 \%$ of the fixed capital costs. ${ }^{20}$ Another study of natural gas plants in Canada using amine gas sweetening methods found that absorbers are typically $10 \%$ of the fixed equipment cost, a regeneration/stripping column $22 \%$, and other equipment (heat exchanger, reboiler, condenser, misc.) comprise the remainder of the costs. ${ }^{5}$ The study also notes that for most natural gas plants, the sweetening process only accounts for $3 \%$ of the capital expenses; liquefaction and other operations within the process account for the remainder. Calculated costs for capital expenses are shown in Table 8.

Table 8. Capital expenditures and operating expenditures based on the design of the absorption column, solvent cost, and volumes of gas processed annually. Relationships based on empirical data collected from Canadian natural gas plants and described in the literature ${ }^{5}$ are used to calculate costs of equipment and labor.

\begin{tabular}{|c|c|c|}
\hline Capital Expenditures & \$ USD & Calculation method \\
\hline Equipment Costs & $\$ 43,866,508$ & \\
\hline Sweetening Equipment Costs & $\$ 1,316,000$ & $\begin{array}{l}\text { Absorption is } 10 \% \text { of total } \\
\text { sweetening equipment costs }\end{array}$ \\
\hline Absorption Equipment & $\$ 131,600$ & $\begin{array}{l}\text { Calculated based on column size, } \\
\text { type, number of trays }\end{array}$ \\
\hline Regeneration Equipment & $\$ 289,520$ & $22 \%$ of sweetening costs \\
\hline Heat Exchangers \& Reboilers & $\$ 736,960$ & $56 \%$ of sweetening costs \\
\hline Misc. & $\$ 210,560$ & $16 \%$ of sweetening costs \\
\hline Other Equipment & $\$ 42,550,667$ & $\begin{array}{l}\text { Sweetening is } 3 \% \text { of total } \\
\text { equipment costs; other costs come } \\
\text { from liquefaction }\end{array}$ \\
\hline Labor Costs & $\$ 263,200,000$ & $6 x$ equipment costs \\
\hline
\end{tabular}

\section{Operating expenditures}

Solvent (99\% recovery)

$\$ 8,000,000 /$ year

Calculated based on soybean oil prices, as shown in Figures 6-7. 
Based on a study of Canadian natural gas plants, natural gas is typically processed at a cost of $\$ 8 / G J$ - where $\$ 4 / G J$ is allocated to pipeline/source costs, leaving $\$ 4 / G J$ for actual treatment and liquefaction of the gas to be sold as liquefied natural gas. ${ }^{5}$ Based on the simple model in Table 8 , which roughly estimates the capital costs and neglects all parts of operating expenditures other than solvent recovery, and assuming the plant has only 5\% downtime but otherwise runs at maximum capacity, a continuous cash flow diagram is shown in Figure 11.

\section{0}

200

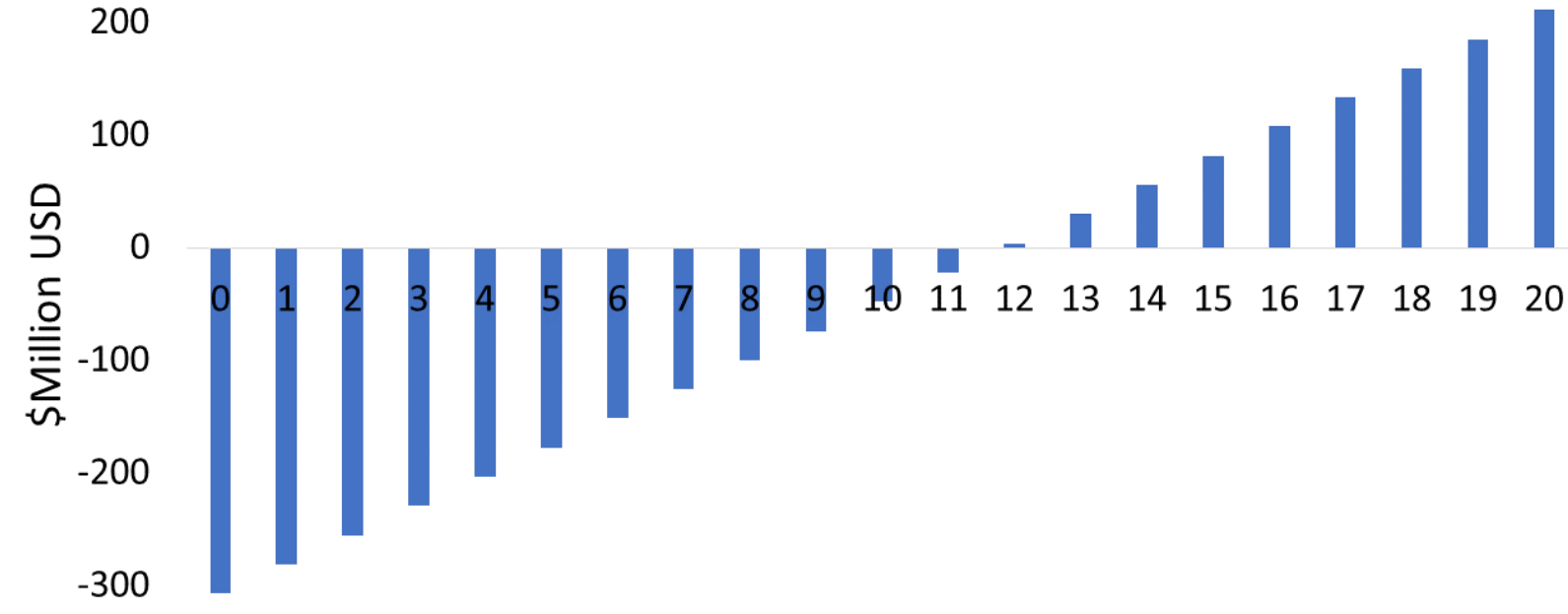

$-400$

Year

Figure 11. Continuous cash flow diagram assuming a 20-year plant and equipment lifetime. Building a new plant would require a large capital investment and the plant would not begin to see profits until year 12. This model also assumes solvent regeneration and re-use is at $99 \%$ and that the cost of processing the gas is even with that of amine gas treating.

After 12 years, the plant would begin to profit. Based on the analysis, over a 20-year plant lifetime, the gas processing cost would be $\$ 3.7 / \mathrm{GJ}$, just under the $\$ 4 / \mathrm{GJ}$ needed to be competitive with amine gas treating and other methods. However, the present model makes several assumptions, including: solvent regeneration and re-use is at $99 \%$, solvent prices do not increase, cost estimates in Table 8 and relationship between cost of different items (i.e. labor $=6 x$ capital costs) are accurate, that natural gas pipelines prices do not increase, that process gas prices do not decrease, 
that the absorption operation of the plant is running at full capacity all but $5 \%$ of each year, and neglects operating costs. A sensitivity analysis showing the relationship between solvent recovery and the cost of processing the gas is shown in Figure 12. Based on the calculations presented, solvent regeneration and re-use would have to exceed $98 \%$ to ensure the costs remain low enough for the overall expense of treating the gas to be comparable with amine gas treating. Increased solvent recovery significantly decreases the cost of treating the gas.

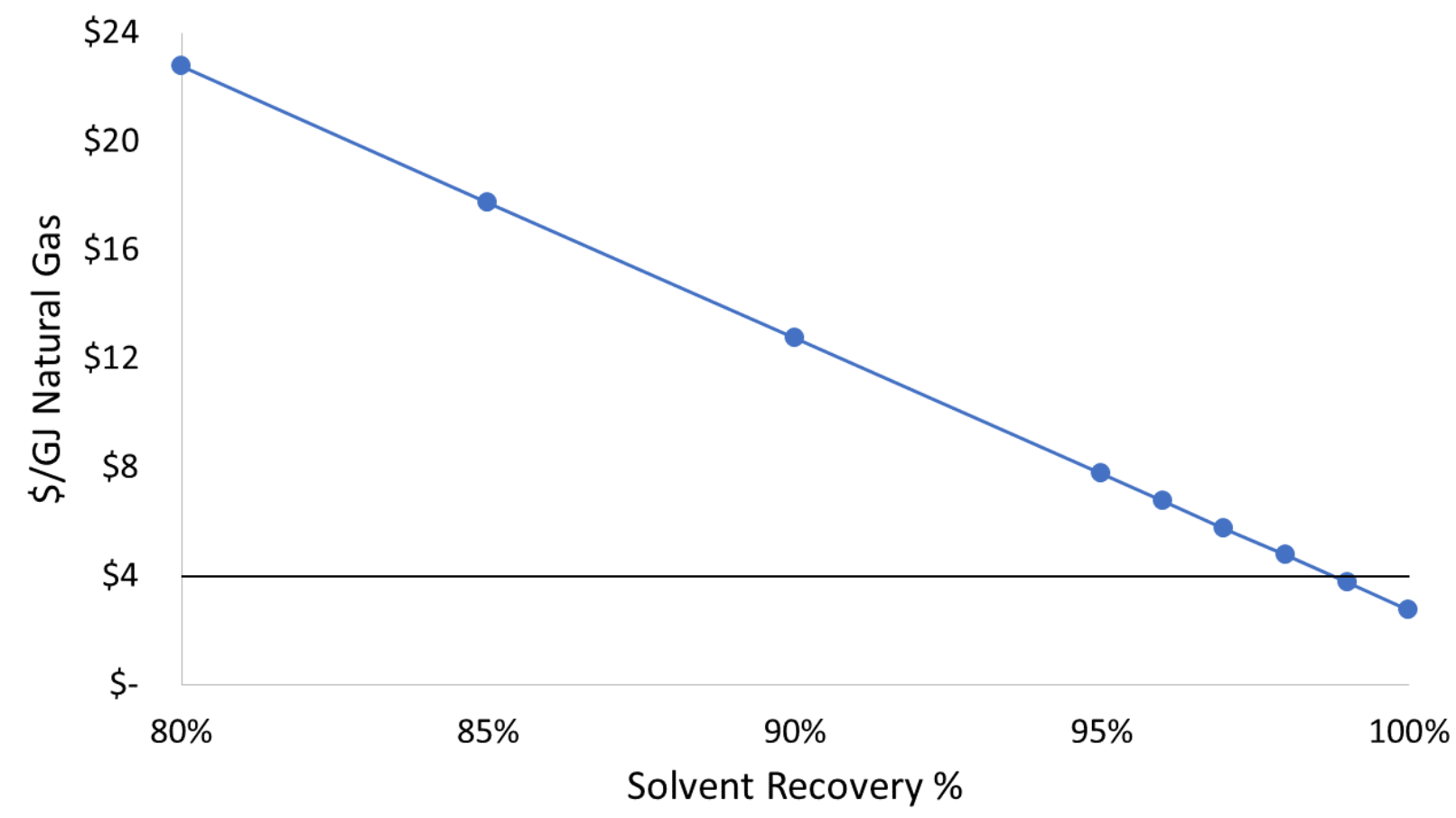

Figure 12. Sensitivity analysis of the relationship between solvent regeneration and recovery and the cost of processing gas. The cost of amine gas sweetening methods is approximately $\$ 4 / G J$ natural gas. To be competitive, the process designed and presented here would need to achieve greater than $98 \%$ solvent regeneration and re-use.

As of yet, a definitive method for stripping the $\mathrm{H}_{2} \mathrm{~S}$ from the soybean oil and bio-solvents and regenerating the bio-oils to be used again is unknown. However, there are a number of methods for recovering $\mathrm{H}_{2} \mathrm{~S}$ gas in aqueous solutions and oils, well-described in the literature. ${ }^{21-24}$ Most methods fall into one of three categories: chemical precipitation, chemical oxidation, or biological oxidation. ${ }^{21-24}$ The key to process viability would be to develop a method that maximizes the percent of the bio-solvent that can be regenerated and re-used. An alternative to the lofty goal of 
98\% solvent regeneration and recovery is to find other avenues in which costs can be reduced. While the price of sweetening is well established in Table 8 , the cost of other equipment is more loosely correlated and estimated, and a full process simulation including other equipment needs may give better insight into the overall process cost and the solvent regeneration percent that must be obtained.

\section{Conclusion}

Soybean oil and high oleic soybean oil were used as case studies to examine viability of using biooils as solvents for extracting $\mathrm{H}_{2} \mathrm{~S}$ from sour natural gas, with an aim of designing an absorption operating that could process $1000 \mathrm{kmol} / \mathrm{h}$ of natural gas and remove $99.9 \%$ of $\mathrm{H}_{2} \mathrm{~S}$ from feed gas ranging from $40-400 \mathrm{ppm} \mathrm{H}_{2} \mathrm{~S}$. Graphical methods and the Kremser method examined the absorption unit and found a trayed tower with 14 stages, a $2 \mathrm{~m}$ diameter and $8.5 \mathrm{~m}$ height, could successfully meet these goals with a soybean oil absorbent flow rate of $120 \mathrm{kmol} / \mathrm{h}$. The cost of such an extraction column was estimated along with other capital costs, and the dependence on the economic viability of such process hinges on capability of regenerating and recycling more than $98 \%$ of the soybean oil bio-solvent to stay competitive with amine gas treating, the most popular industrial method. The potential of the proposed process being economically favorable looks unlikely. However, we show here where cost-cutting measures could be developed and implemented to reduce processing cost so that bio-based oils are able to compete with current technologies. 


\section{Notation}

\begin{tabular}{|c|c|}
\hline$A$ & Separation factor \\
\hline$A_{d} / A$ & Ratio of active tray area to total tray area \\
\hline$C$ & Flooding capacity parameter \\
\hline$C_{F}$ & Flooding capacity velocity \\
\hline $\mathrm{CH}_{4}$ & Methane \\
\hline $\mathrm{CO}_{2}$ & Carbon dioxide \\
\hline$D_{T}$ & Column diameter \\
\hline$f$ & Flooding capacity \\
\hline$F_{F}$ & Foaming factor \\
\hline$F_{H A}$ & Factor for ratio of vapor hole area to tray active area \\
\hline$F_{L V}$ & Entrainment flooding capacity \\
\hline$F_{S T}$ & Surface tension factor \\
\hline$G^{\prime}$ & Feed gas flow rate \\
\hline HOSBO & High-oleic soybean oil \\
\hline $\mathrm{H}_{2} \mathrm{~S}$ & Hydrogen sulfide \\
\hline$K$ & Partition coefficient \\
\hline$L$ & Liquid flow rate \\
\hline$L^{\prime}$ & Absorbent flow rate \\
\hline$L^{\prime} \min$ & Minimum absorbent flow rate \\
\hline$L^{\prime}{ }_{o p t}$ & Optimal absorbent flow rate \\
\hline$M_{L}$ & Molar mass of liquid \\
\hline$M_{V}$ & Molar mass of vapor \\
\hline$N$ & Number of stages \\
\hline$S B O$ & Conventional soybean oil \\
\hline$U_{f}$ & Flooding velocity \\
\hline$V$ & Vapor flow rate \\
\hline$X_{N}$ & Concentration of $\mathrm{H} 2 \mathrm{~S}$ in the gas phase at stage $N$ \\
\hline$Y_{N}$ & Concentration of $\mathrm{H} 2 \mathrm{~S}$ in the liquid phase at stage $N$ \\
\hline$\sigma$ & Surface tension \\
\hline$\rho_{L}$ & Liquid density \\
\hline$\rho_{V}$ & Vapor density \\
\hline
\end{tabular}




\section{Declarations}

Acknowledgements

The authors thank the funding opportunity from Indiana Soybean Alliance (ISA 16056097) and Indiana Hatch Project No. IND010677. This work was completed as part of ECB's doctoral thesis.

Authors' contributions

ECB and ASE designed the study. ECB performed all of experiments and carried out the initial analysis. ECB and ASE wrote the manuscript. All authors read and approved the final manuscript.

Funding

The authors are grateful for the financial support received from Indiana Soybean Alliance (ISA 16056097) and Indiana Hatch Project No. IND010677.

Availability of data and materials

The authors approved the availability of data and materials for publishing the manuscript.

Ethics approval and consent to participate

All the authors have read and agreed the ethics for publishing the manuscript.

Consent for publication

The authors approved the consent for publishing the manuscript.

Competing interests

The authors declare that they have no competing interests.

\section{References}

1. Brace EC, Engelberth AS. Assessing Viability of Soybean Oils to Remove Hydrogen Sulfide from Natural Gas. ACS Sustain Chem Eng. 2020;8(25):9377-9384. doi:10.1021/acssuschemeng.0c01991

2. Acid Gas Removal. Natl Energy Technol Lab.

3. Eow JS. Recovery of sulfur from sour acid gas: A review of the technology. Environ Prog. 2002;21(3):143-162. doi:10.1002/ep.670210312

4. Polasek JC, Bullin JA, Iglesias-Silva GA. Using Mixed Amine Solutions for Gas Sweetening.; 2006.

5. Raj R, Suman R, Ghandehariun S, Kumar A, Tiwari MK. A techno-economic assessment of the liquefied natural gas (LNG) production facilities in Western Canada. Sustain Energy 
Technol Assessments. 2016;18:140-152. doi:10.1016/j.seta.2016.10.005

6. Sulfur Recovery and Tail Gas Treating. Natl Energy Technol Lab.

7. Seader JD, Henley EJ. Separation Process Principles. 1st ed. John Wiley \& Sons; 1998.

8. Kremser A. Theoretical Analysis of Absorption Process. Natl Pet News. 1930;22(21):4349.

9. Oliver ED. Diffusional Separation Processes: Theory, Design, and Evaluation. John Wiley and Sons; 1966.

10. Patzek TW. A First Law Thermodynamic Analysis of Biodiesel Production From Soybean.; 2009.

11. Sahasrabudhe SN, Rodriguez-Martinez V, Farkas BE. International Journal of Food Properties Density, viscosity, and surface tension of five vegetable oils at elevated temperatures: Measurement and modeling. 2017. doi:10.1080/10942912.2017.1360905

12. Turton R, Bailie RC, Whiting WB, Shaeiwitz JA, Bhattacharyya D. Analysis, Synthesis, and Design of Chemical Processes. 4th ed. Upper Saddle River, NJ: Prentice Hall; 2012.

13. Jenkins S. 2019 Chemical Engineering Plant Cost Index Annual Average. Chem Eng. March 2020.

14. U.S. Soybean Oil: U.S. Production History |.

15. Food + Fuel| U.S. Soy.

16. Fakhry R. The Myth of the 24/7/365 Power Plant. Nat Resour Def Counc. February 2019.

17. Dalrymple D, Trofe T, States) JE-CEP ;(Unite., 1989 undefined. An overview of liquid redox sulfur recovery. osti.gov.

18. Pandey RA, Malhotra S. Desulfurization of Gaseous Fuels with Recovery of Elemental Sulfur: An Overview. Crit Rev Environ Sci Technol. 1999;29(3):229-268. 
doi:10.1080/10643389991259236

19. U.S. Natural Gas Prices.

20. Ochieng R, Berrouk AS, Peters CJ, Slagle J. Amine-Based Gas-Sweetening Processes Prove Economically More Viable than the Benfield HiPure Process.

21. Zhang L, De Schryver P, De Gusseme B, De Muynck W, Boon N, Verstraete W. Chemical and biological technologies for hydrogen sulfide emission control in sewer systems: A review. Water Res. 2008;42(1-2):1-12. doi:10.1016/J.WATRES.2007.07.013

22. Shiraishi Y, Tachibana K, Hirai T, Komasawa I. Desulfurization and Denitrogenation Process for Light Oils Based on Chemical Oxidation followed by Liquid-Liquid Extraction. Ind Eng Chem Res. 2002;41(17):4362-4375.

23. Yu G, Lu S, Chen H, Zhu Z. Oxidative Desulfurization of Diesel Fuels with Hydrogen Peroxide in the Presence of Activated Carbon and Formic Acid. Energy \& Fuels2. 2005;19(2):447-452.

24. Syed M, Soreanu G, Falletta P, Béland M. Removal of hydrogen sulfide from gas streams using biological processes -A review. Can Biosyst Eng. 2006;48(21). 


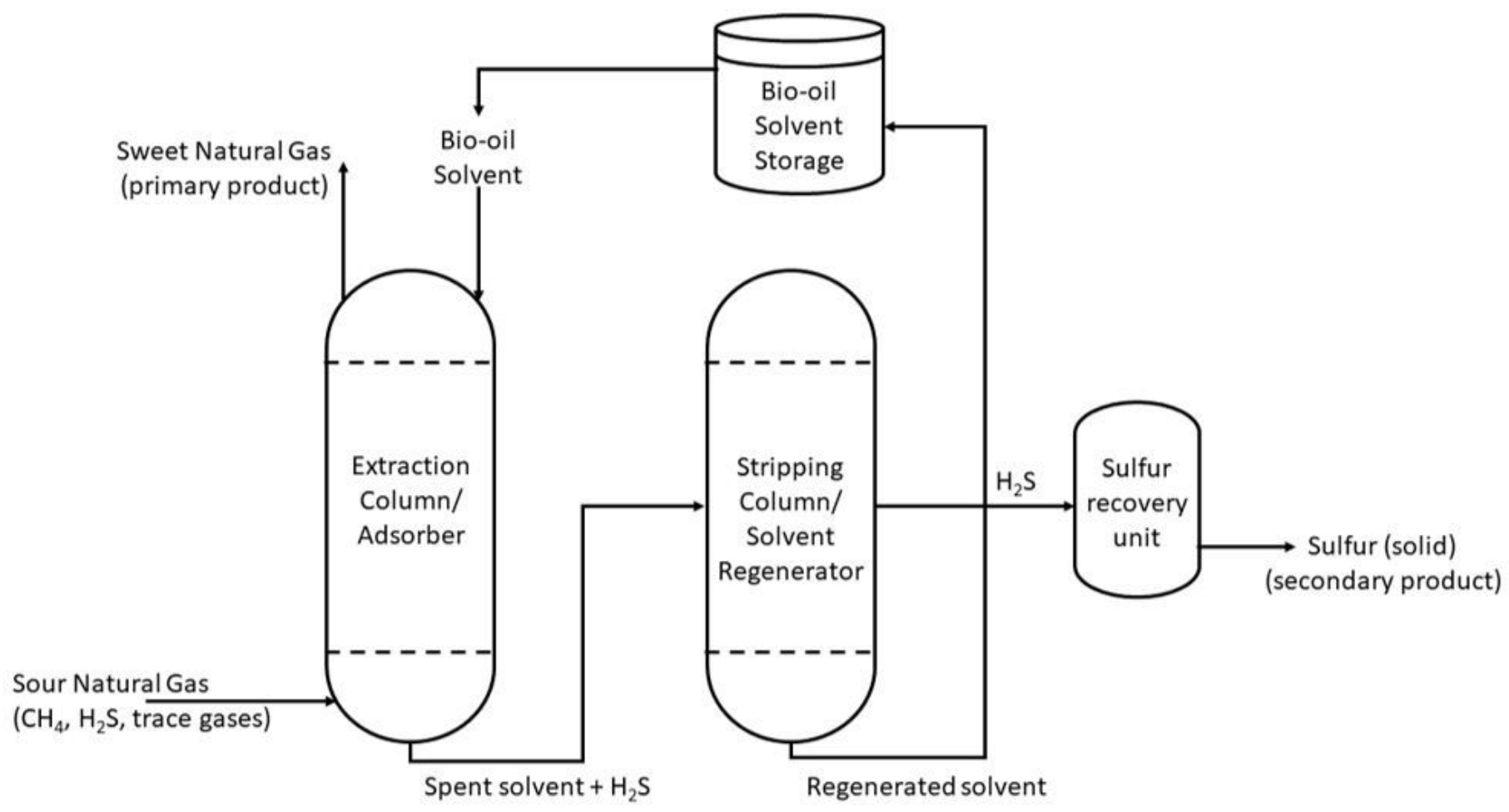

\section{Figure 1}

Schematic diagram of a potential process using bio-oil as an extraction solvent to remove $\mathrm{H} 2 \mathrm{~S}$ from sour natural gas. An extraction column and solvent cost will be the primary initial costs and will be used to set a limit on how much the solvent regeneration/sulfur recovery units could cost in order for the total process to be economically viable. 
(a)

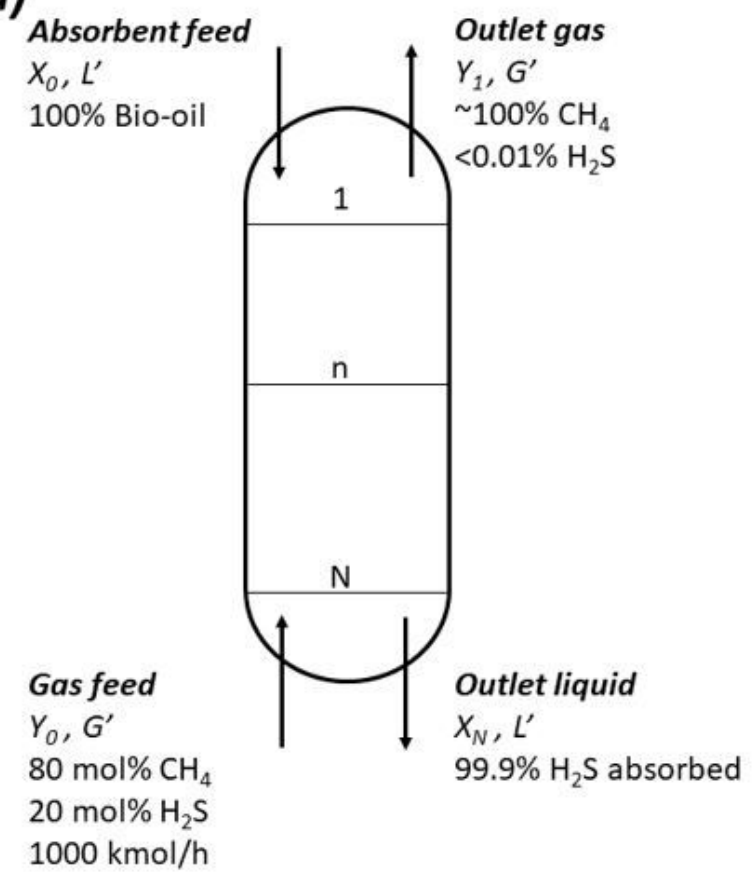

(b)

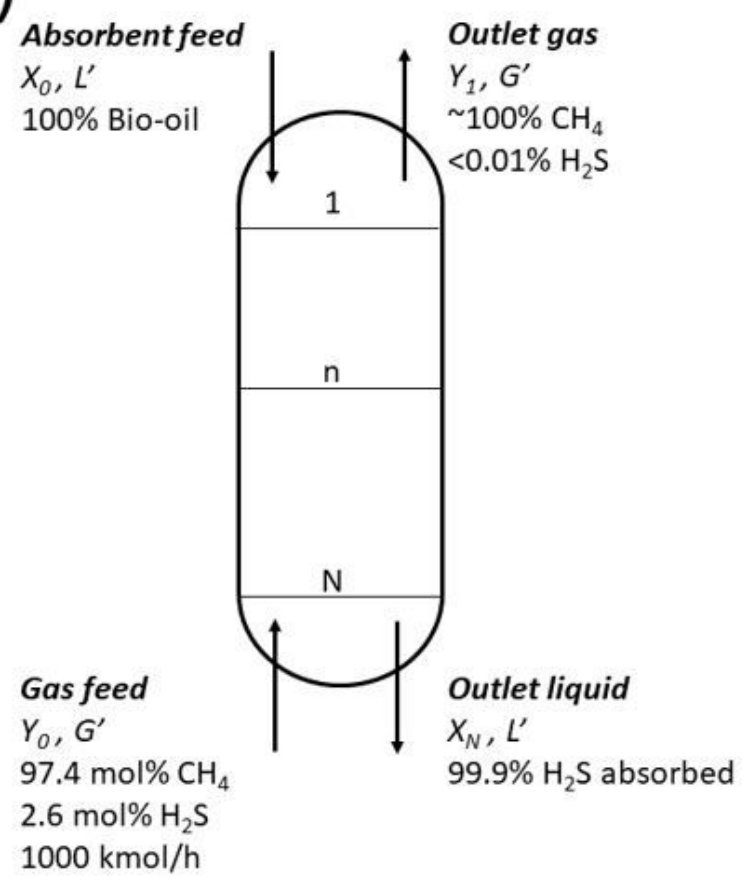

\section{Figure 2}

A tray column absorption unit operation with a gas feed of either (a) $20 \mathrm{~mol} \% \mathrm{H} 2 \mathrm{~S}$ ( 400ppmv) or (b) 2.6 mol\% H2S ( 40ppmv). Based on a feed gas flowrate ( $\left.G^{\prime}\right)$ of $1000 \mathrm{kmol} / \mathrm{h}$, the absorbent flow rate $L^{\prime}$ and number of stages $\mathrm{N}$ necessary to achieve $99.9 \%$ removal of the $\mathrm{H} 2 \mathrm{~S}$ from the gas feed was determined using a graphical method. 

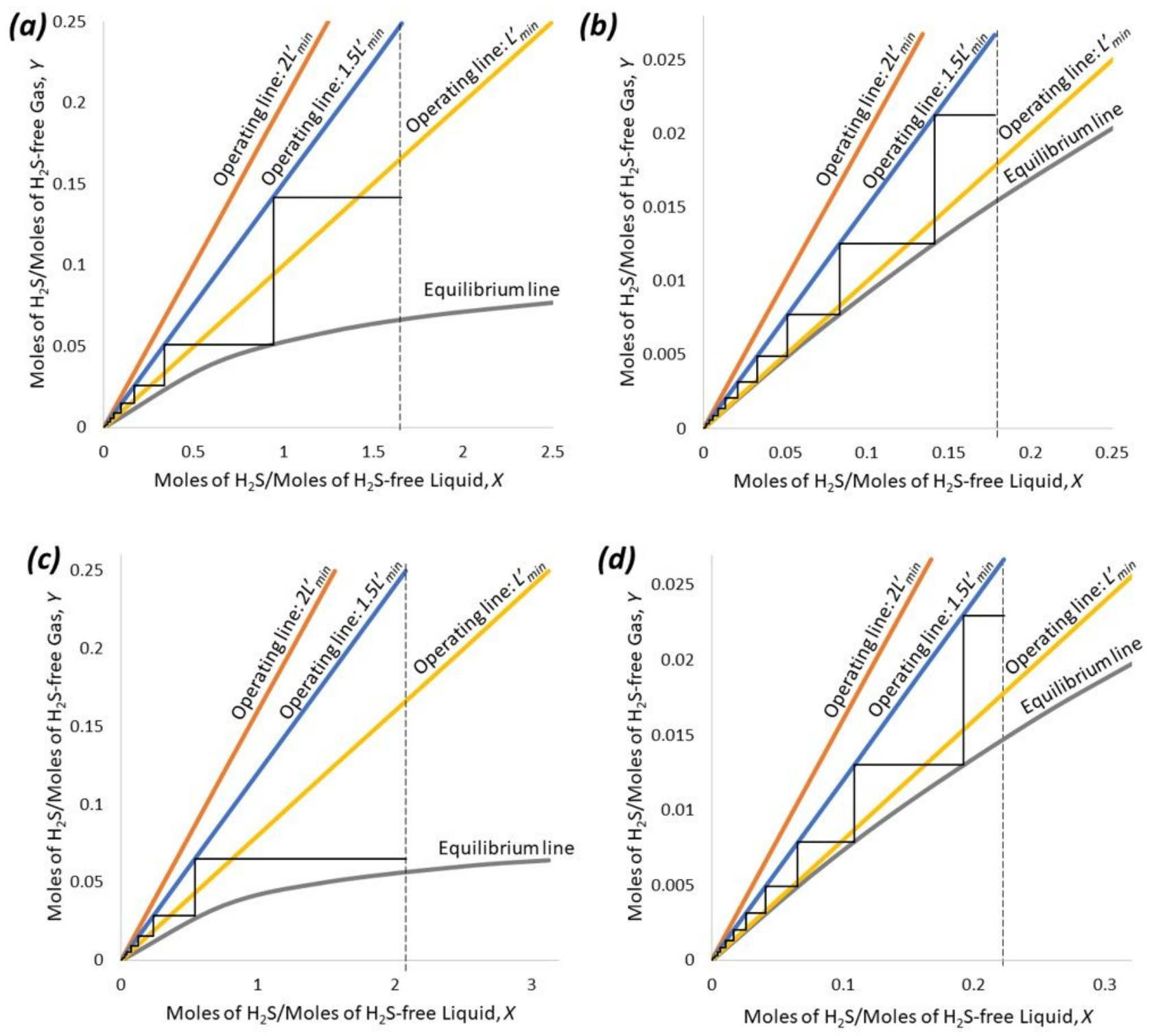

\section{Figure 3}

A graphical solution to determine the number of stages necessary for removing $99.9 \%$ of $\mathrm{H} 2 \mathrm{~S}$ from a feed gas of (a) $20 \mathrm{~mol} \% \mathrm{H} 2 \mathrm{~S}$ in methane, HOSBO; (b) $2.6 \mathrm{~mol} \% \mathrm{H} 2 \mathrm{~S}$ in methane, HOSBO; (c) $20 \mathrm{~mol} \% \mathrm{H} 2 \mathrm{~S}$ in methane, SBO; (d) $2.6 \mathrm{~mol} \% \mathrm{H} 2 \mathrm{~S}$ in methane, SBO. The operating lines are based on the flow rate of the absorbent feed. The equilibrium line is based on the partition coefficient $\mathrm{K}$ of $\mathrm{H} 2 \mathrm{~S}$ in the absorbent, high oleic soybean oil, previously determined to be 0.1 . The graphical solution is completed for the optimum operating line of 1.5L'min, and the number of stages $\mathrm{N}$ was determined to be (a) 10.2 (b) 13.3 (c) 9.6 and (d) 14.2 stages. 

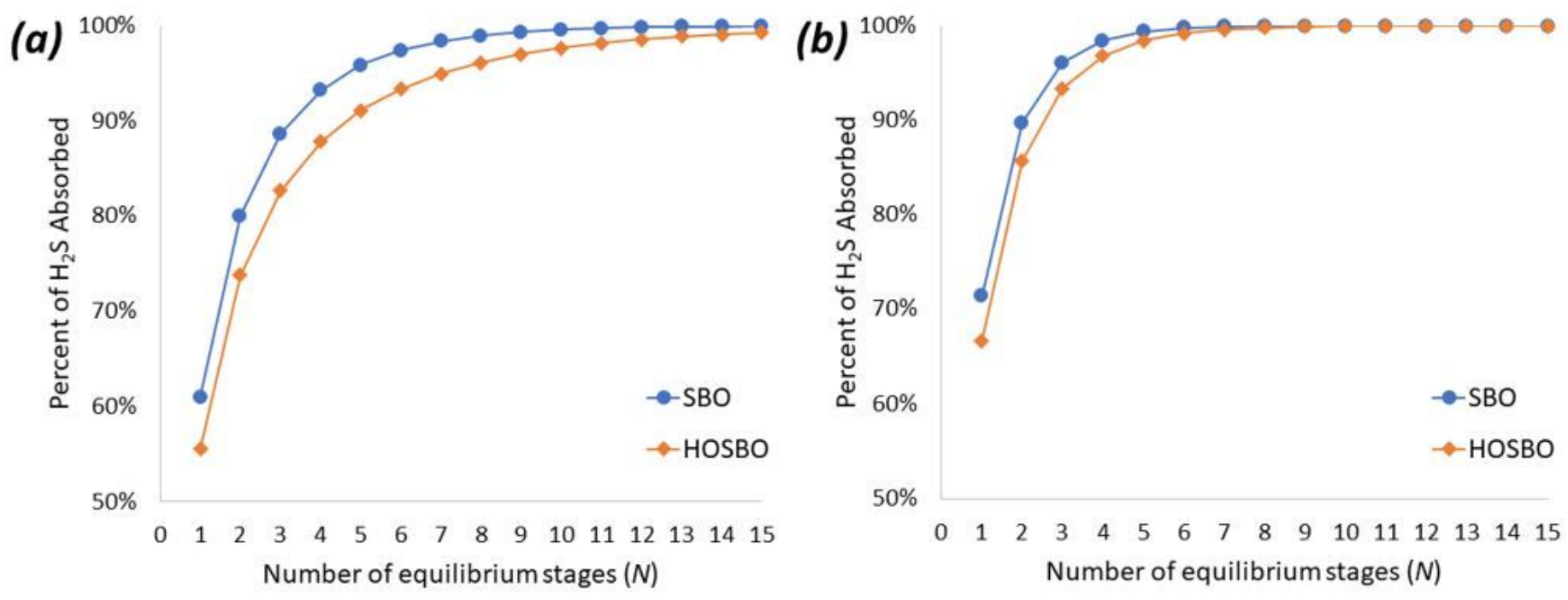

Figure 4

The percent of $\mathrm{H} 2 \mathrm{~S}$ recovered at each equilibrium stage is dependent by each oil at absorbent flow rates (L) of (a) $125 \mathrm{kmol} / \mathrm{h}$ and (b) $200 \mathrm{kmol} / \mathrm{h}$. The percent of $\mathrm{H} 2 \mathrm{~S}$ recovered is a function of the absorbent flow rate, the feed gas flow rate $(V=1000 \mathrm{kmol} / \mathrm{h})$, and the $\mathrm{K}$ value for $\mathrm{H} 2 \mathrm{~S}$ in each oil $(0.08$ for $\mathrm{SBO}, 0.1$ for HOSBO), as shown in Equations 5 and 6.

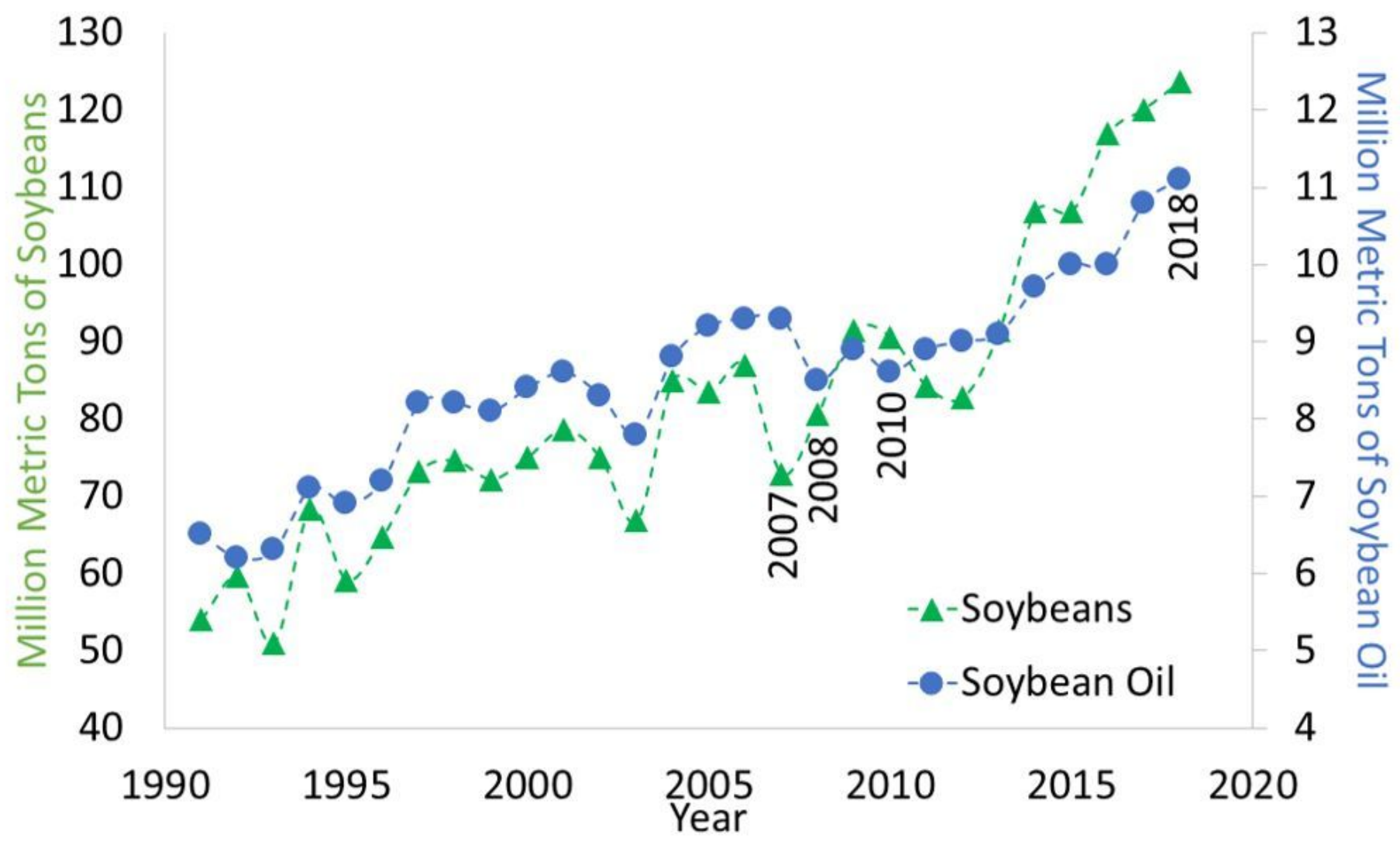

Figure 5 
Soybean and soybean oil production in the United States, 1991 - 2018. Soybean oil production is about $10 \%$ (by mass) of soybean production overall and has continued to rise from 2010 - present.

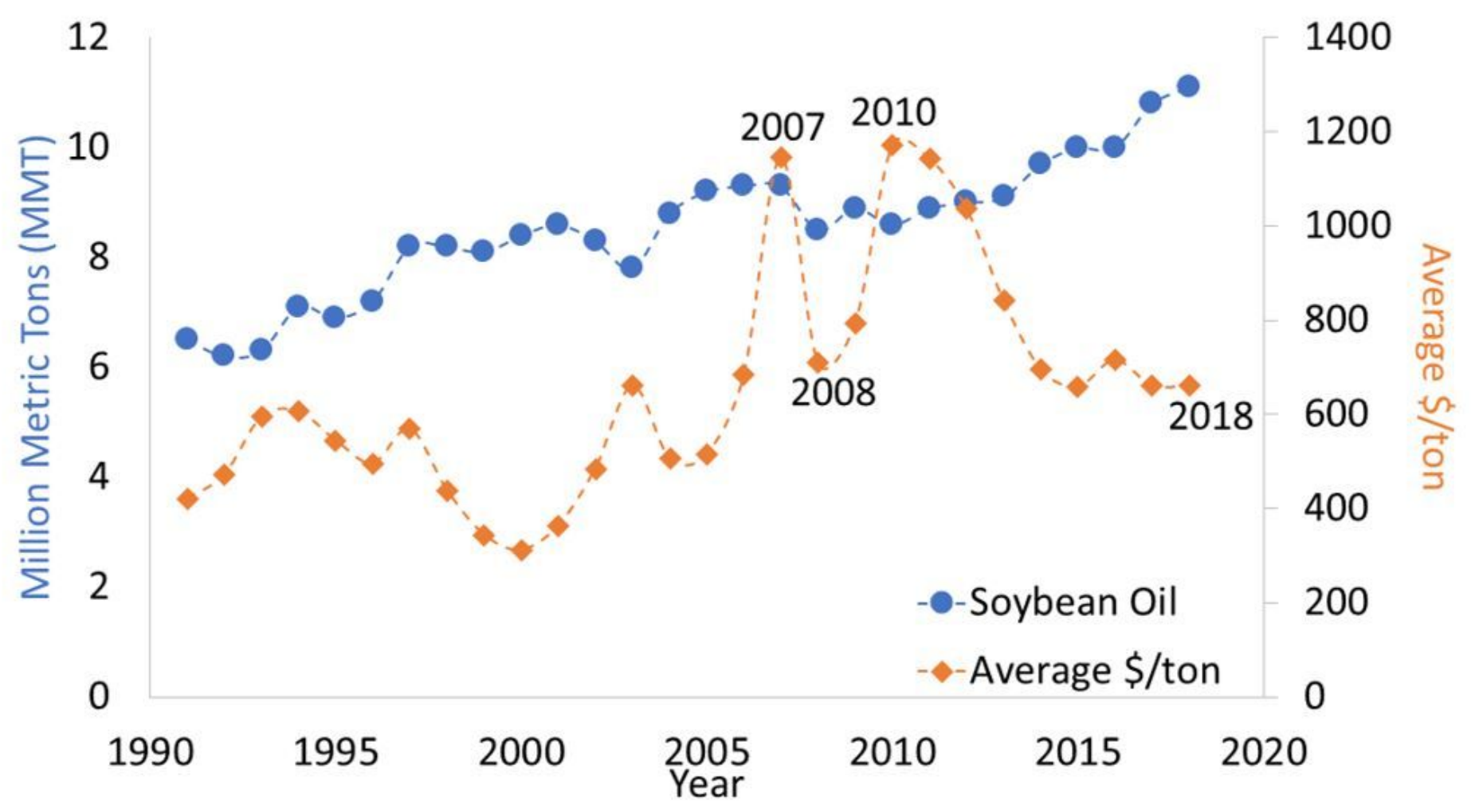

Figure 6

U.S. Soybean oil production and prices from $1991-2018$. 


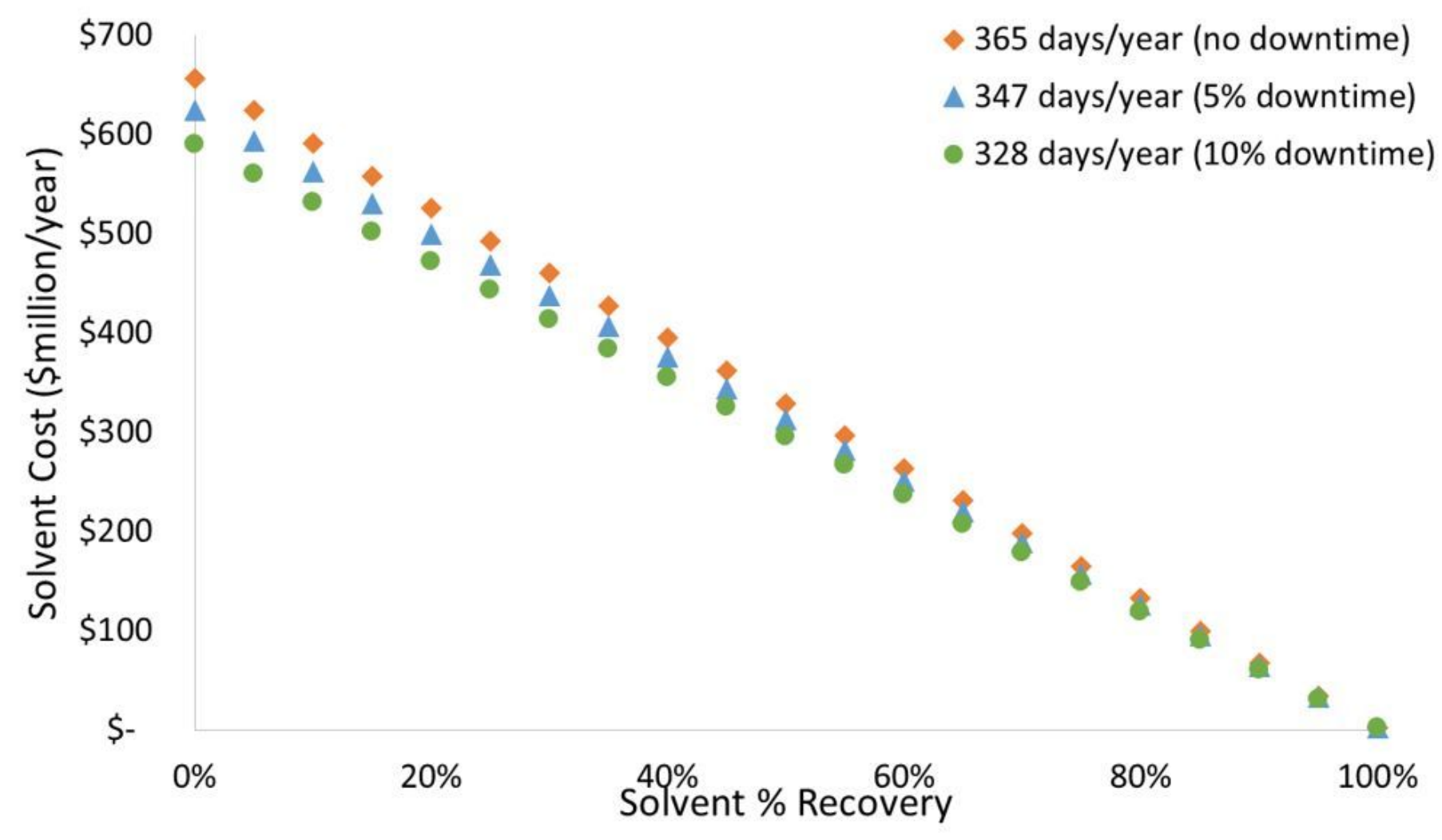

Figure 7

Solvent cost of using soybean oil ( $\$ 679 /$ ton) depending on the amount of solvent that can be recovered and re-used, and the anticipated downtime of the absorption unit of the plant. For a plant operating $95 \%$ of the year, solvent cost with no recovery would amount to $\$ 624$ million/year, but even $50 \%$ of solvent recovery would result in a solvent cost of $\$ 312$ million/year. 


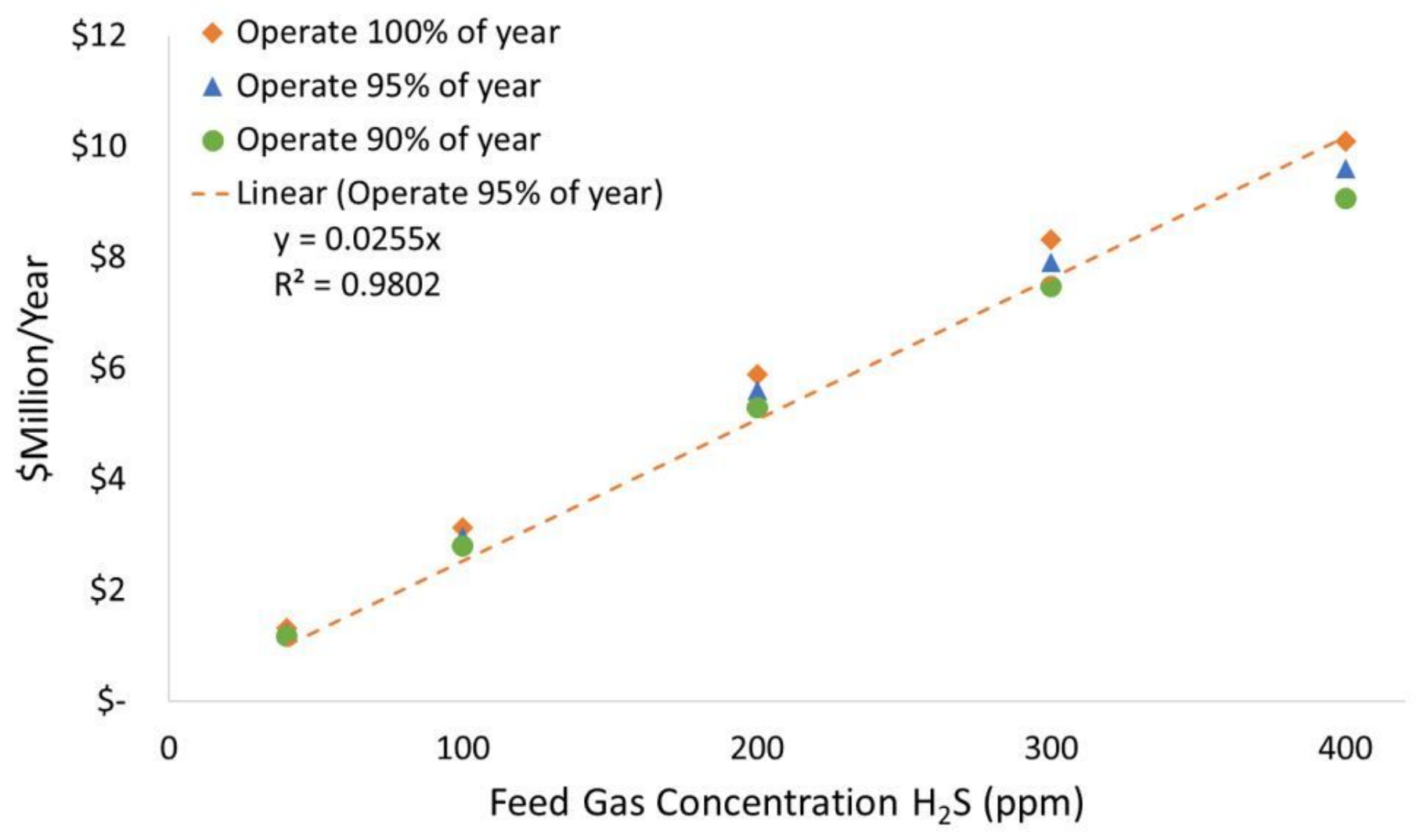

Figure 8

Assuming that $90 \%$ of all $\mathrm{H} 2 \mathrm{~S}$ processed is successfully captured and converted to sulfur, revenues from $\$ 1.2$ - $\$ 10$ million annually can be anticipated from sulfur sales. This is dependent on the concentration of $\mathrm{H} 2 \mathrm{~S}$ in the feed gas being processed throughout the year, as well as the portion of the year the plant is online and operating (assuming the absorption unit is at full capacity and online for the same percent of the year as the plant). Processing more sour gas (400 ppm) would lead to higher revenues than less sour gas (40 ppm). If the plant and absorption unit are online and full capacity $95 \%$ of the year, and the average feed gas concentration for the year was 200 ppm H2S, an annual revenue of approximately $\$ 5.6$ million could be expected. This would correspond to selling 28,000 tons of sulfur per year. 


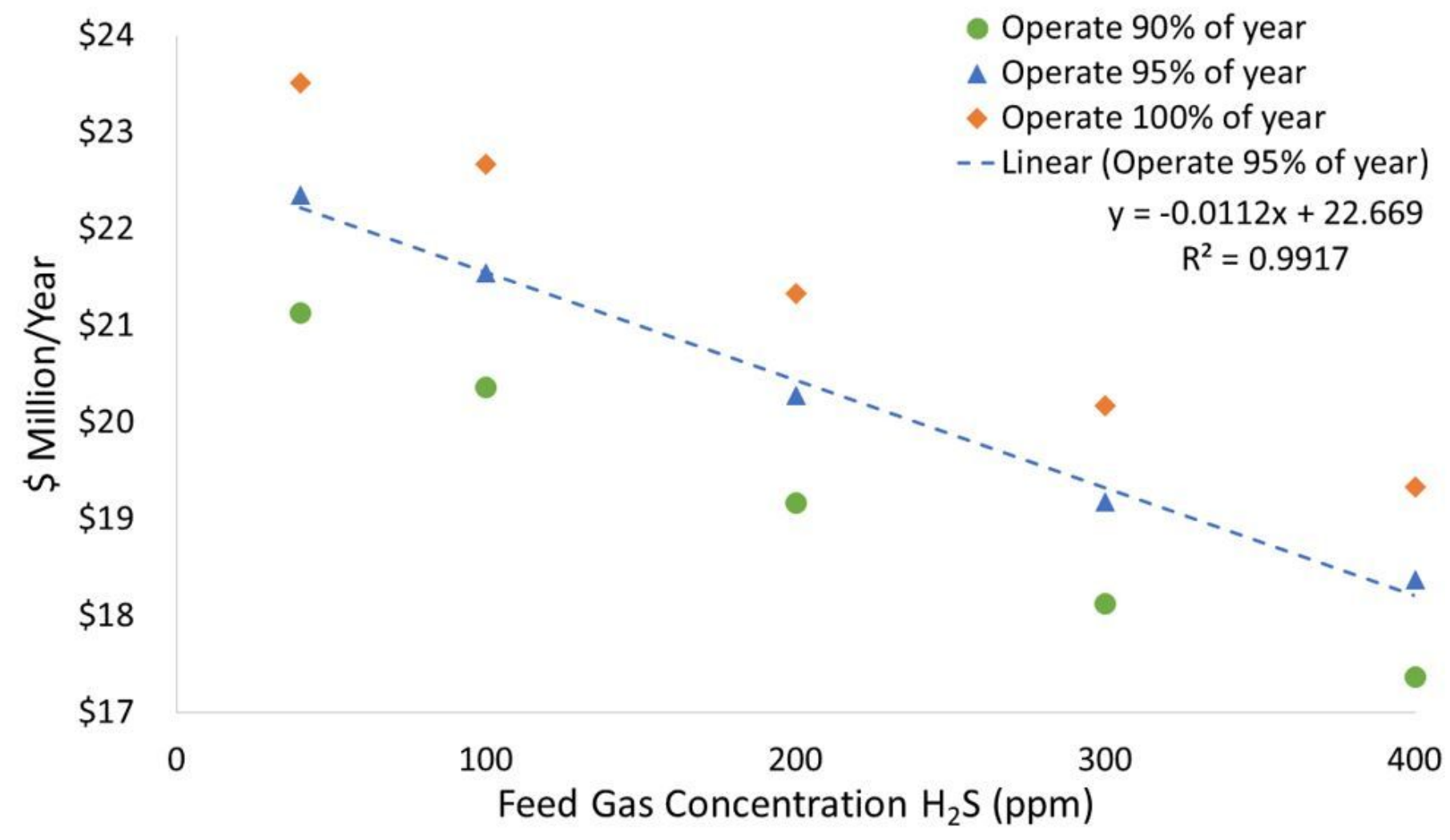

Figure 9

Annual revenue from processing natural gas.

$\$ 30$

n NATURAL GAS $=$ SULFUR

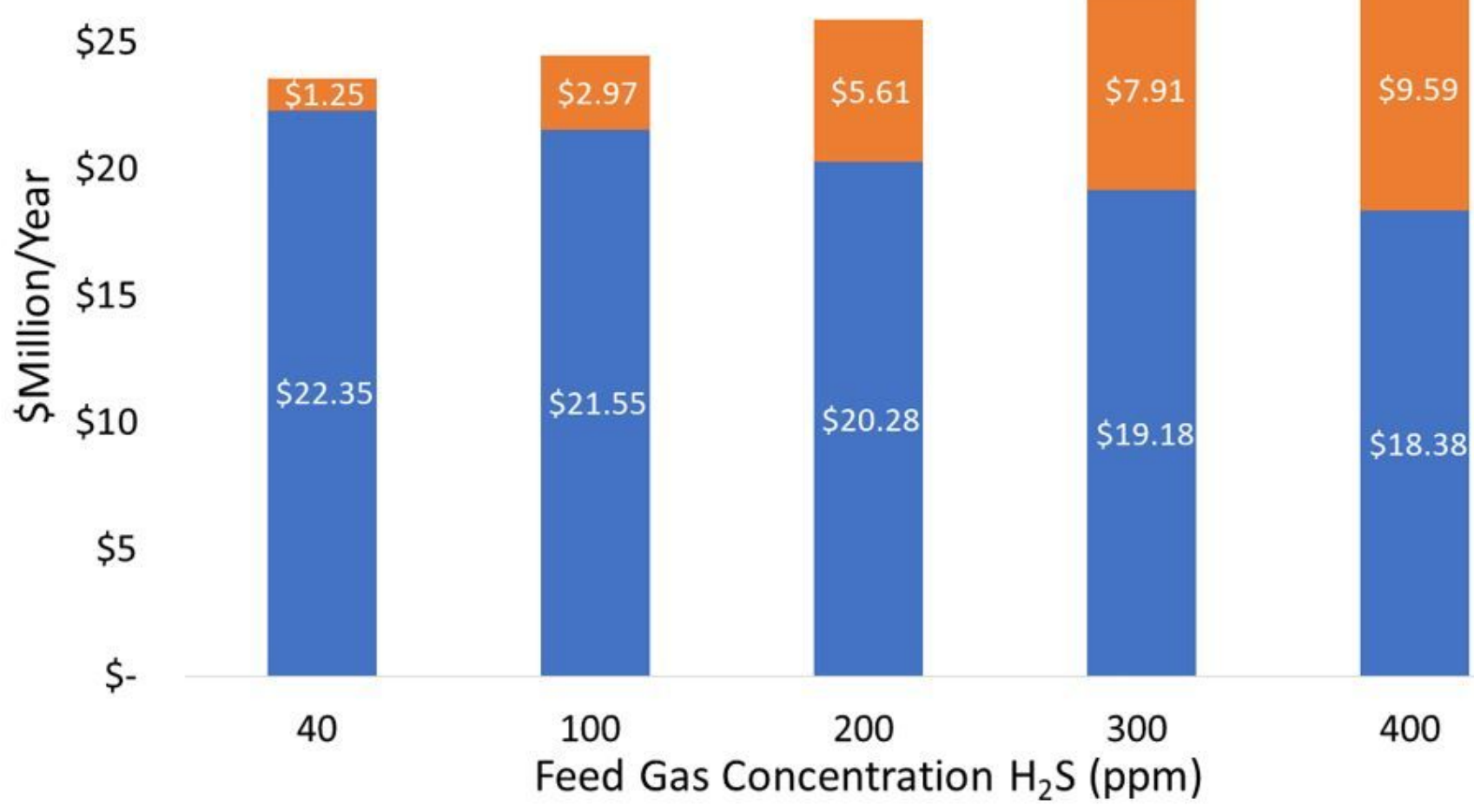


Figure 10

Revenue generated by the designed absorption unit operating with $5 \%$ downtime annually, $100 \%$ recovery of $\mathrm{CH} 4$, and $90 \%$ recovery and conversion of $\mathrm{H} 2 \mathrm{~S}$ to elemental sulfur. As feed gas becomes increasingly sour, although amount of sweet gas for sale will decrease, sales of sulfur will increase and increase the total revenue.

\section{0}

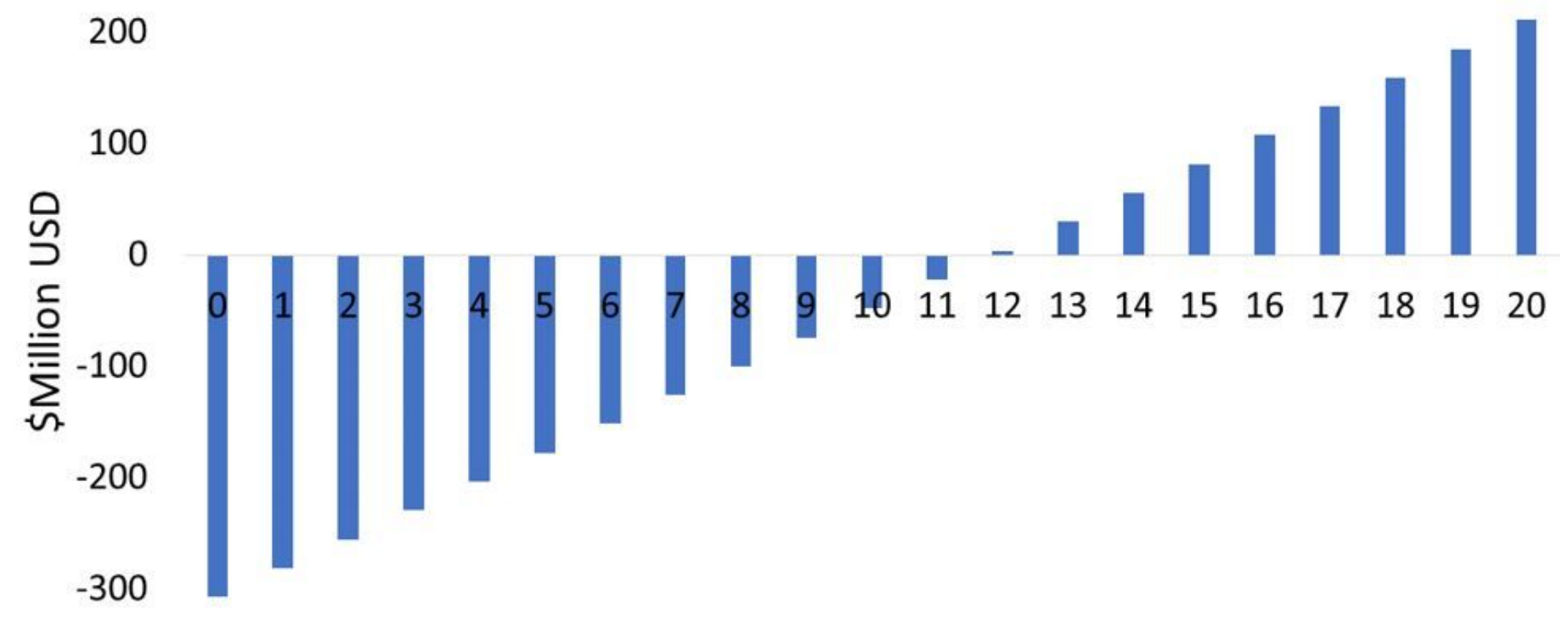

$-400$

\section{Year}

\section{Figure 11}

Continuous cash flow diagram assuming a 20-year plant and equipment lifetime. Building a new plant would require a large capital investment and the plant would not begin to see profits until year 12 . This model also assumes solvent regeneration and re-use is at $99 \%$ and that the cost of processing the gas is even with that of amine gas treating. 


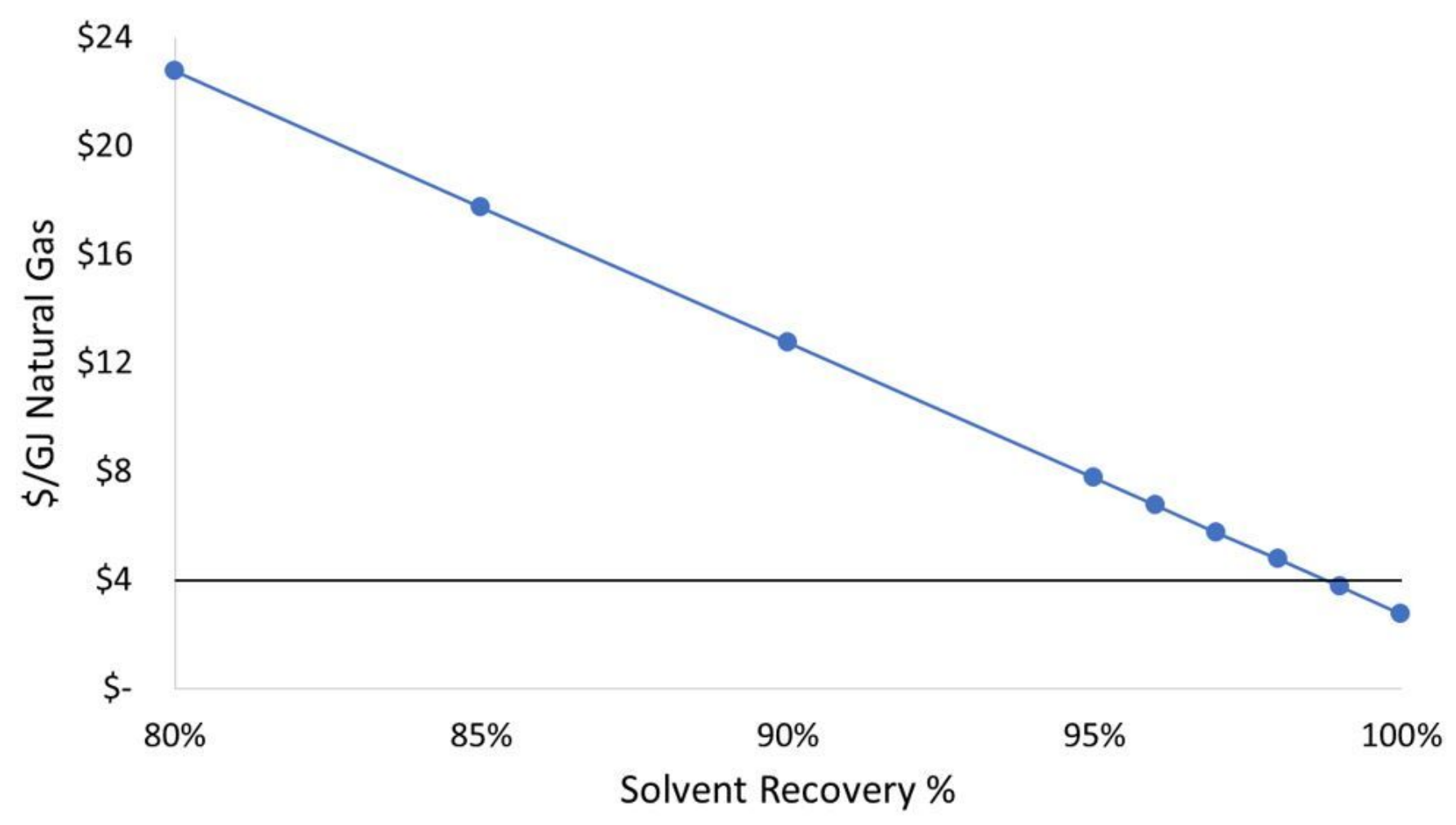

Figure 12

Sensitivity analysis of the relationship between solvent regeneration and recovery and the cost of processing gas. The cost of amine gas sweetening methods is approximately $\$ 4 / G J$ natural gas. To be competitive, the process designed and presented here would need to achieve greater than $98 \%$ solvent regeneration and re-use.

\section{Supplementary Files}

This is a list of supplementary files associated with this preprint. Click to download.

- BIOBGraphicalAbstractBrace.tiff 